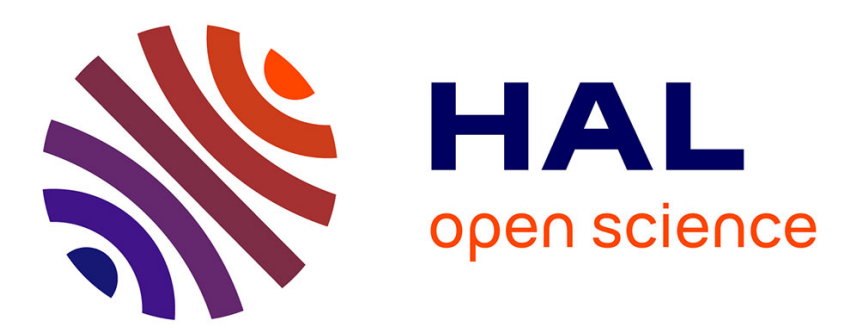

\title{
La différenciation ovarienne précoce et son contrôle génétique
}

\author{
Adrienne Baillet, Béatrice Mandon-Pepin, Reiner Veitia, Corinne Cotinot
}

\section{To cite this version:}

Adrienne Baillet, Béatrice Mandon-Pepin, Reiner Veitia, Corinne Cotinot. La différenciation ovarienne précoce et son contrôle génétique. Différenciation et régulation des fonctions ovariennes: nouveaux concepts, Jun 2011, Paris, France. pp.201-221, 10.1051/jbio/2011021 . hal-01019059

\section{HAL Id: hal-01019059 \\ https://hal.science/hal-01019059}

Submitted on 29 May 2020

HAL is a multi-disciplinary open access archive for the deposit and dissemination of scientific research documents, whether they are published or not. The documents may come from teaching and research institutions in France or abroad, or from public or private research centers.
L'archive ouverte pluridisciplinaire HAL, est destinée au dépôt et à la diffusion de documents scientifiques de niveau recherche, publiés ou non, émanant des établissements d'enseignement et de recherche français ou étrangers, des laboratoires publics ou privés. 
Biologie Aujourd'hui, 205 (4), 201-221 (2011)

(C) Société de Biologie, 2012

DOI: $10.1051 / \mathrm{jbio} / 2011021$

\title{
La différenciation ovarienne précoce et son contrôle génétique
}

\author{
Adrienne Baillet ${ }^{1}$, Béatrice Mandon-Pépin ${ }^{2}$, Reiner Veitia ${ }^{3,4}$ et Corinne Cotinot ${ }^{2}$ \\ ${ }^{1}$ Laboratoire de Génétique et Biologie Cellulaire, EA 4589 Université de Versailles Saint-Quentin-en-Yvelines, \\ École Pratique des Hautes Études, 78035 Versailles Cedex, France \\ 2 INRA, UMR1198, Biologie du Développement et Reproduction, 78352 Jouy-en-Josas, France \\ ${ }^{3}$ CNRS UMR 7592, Institut Jacques Monod, Équipe Génétique et Génomique du Développement Gonadique, \\ 75205 Paris Cedex 13, France \\ ${ }^{4}$ Université Paris Diderot-Paris VII, 75205 Paris Cedex 13, France
}

Auteur correspondant : Corinne Cotinot, corinne.cotinot@jouy.inra.fr

Reçu le 30 juin 2011

\begin{abstract}
Résumé - La différenciation de l'ovaire a été considérée pendant plusieurs décennies comme un processus passif, se mettant en place par défaut. Le développement d'outils génétiques permettant l'invalidation de gènes chez la souris, d'approches transcriptomiques hautdébit ainsi que l'étude de modèles animaux pertinents a montré que la différenciation des gonades est un processus dynamique dans les deux sexes et a permis d'identifier des acteurs clés de la différenciation ovarienne. La détermination des cellules somatiques de l'ovaire est sous le contrôle de deux voies majeures, l'une régulée par le facteur de transcription FOXL2 avec ou sans les œestrogènes selon les espèces, et celle de la voie $\beta$-caténine (Rspo1, Wnt4, $\beta$-caténine). Ces deux cascades géniques agissent simultanément sur l'activation de la voie femelle et l'inactivation de la voie mâle. À l'inverse, la différenciation sexuelle des cellules germinales ne résulte pas uniquement du contenu chromosomique de la cellule (XX femelle et XY mâle). Elle est le résultat de l'environnement des gonocytes dans l'ébauche gonadique. Très tôt, les gonocytes femelles vont se multiplier par mitose puis s'engager dans la méiose (prophase I). Suivra la formation des follicules primordiaux, étape cruciale de la vie reproductive femelle car elle constitue la réserve ovarienne. Les connaissances sur les facteurs qui participent à ces processus moléculaires ont beaucoup progressé au cours des dix dernières années et seront présentées dans cette revue.
\end{abstract}

Mots clés : Détermination du sexe / ovaire / méiose / folliculogenèse

Abstract - Genetics of early ovarian differentiation: recent data.

Early ovarian development has long been thought of as a default pathway switched on passively by the absence of $S R Y$ gene. Recent genetic and transcriptomic studies challenge this view and show that two master pathways simultaneously repress male-specific genes and activate female-specific genetic cascades. This antagonistic action is maintained from embryonic stages to adulthood. The differentiation of the ovarian somatic component is regulated by both the forkhead transcription factor FOXL2 (alone or in combination with oestrogens according to the species) and $\beta$-catenin pathway activated by Wnt4 and Rspo1. The sex-specific change in the fate of primordial germ cells depends on the gonad environment. Female gonocytes actively proliferate by mitosis then enter meiosis I until the diplotene stage. Primordial follicle formation occurs when oocytes are individually surrounded with pre-granulosa cells. In mammals, the population of primordial follicles serves as a resting and finite pool of oocytes available during the female reproductive life span. Recent data on factors controlling these molecular processes will be presented in this review.

Key words: Sex determination / ovary / meiosis / prophase I / ovarian folliculogenesis 


\author{
Abréviations \\ AMH: Anti-Müllerian Hormone \\ AR: Acide Rétinoïque \\ BPES: Blepharophimosis, Ptosis, Epicantus inversus \\ Syndrome \\ Dax1: Dosage-sensitive sex reversal, adrenal hypopla- \\ sia critical region, on chromosome $X$, gene 1 \\ Dhh: Desert hedgehog \\ ESR: Estrogen Receptor \\ Fst: Follistatine \\ Inhbb: Inhibine beta B \\ jpc: jour post-conception \\ jpp: jour post-partum \\ OGCT: Ovarian Granulosa Cell Tumour \\ RSPO: member of the R-SPOndin family \\ SOHLH: Spermatogenesis and Oogenesis basic Helix- \\ Loop-Helix transcription factor \\ SR Y: Sex determining Region of $Y$ chromosome \\ SOX9: SRY-box 9 \\ TES: Testis-specific Enhancer of SOX9
}

\section{Introduction}

À la suite des expériences menées par Alfred Jost (Jost et al., 1947 ; Jost, 1972), montrant que la castration de fœetus de lapin femelles permettait le développement d'organes génitaux internes et externes de type femelle, il a été conclu que le développement de l'appareil génital femelle ne nécessitait pas la présence d'hormones. Ceci est à l'inverse de ce qui se passe chez le mâle, pour lequel le testicule et les hormones qu'il produit sont indispensables au développement de l'appareil génital interne et externe mâle. De cette expérimentation, un concept a été déduit, selon lequel le sexe femelle se différenciait par défaut, alors qu'il ne s'agissait ici que du sexe phénotypique des organes génitaux externes. Cette sur-interprétation de l'expérience princeps, qui ne portait pas sur la différenciation des gonades, amène encore aujourd'hui à lire ou entendre que la différenciation ovarienne et plus largement femelle s'établit par défaut.

Depuis les années 60, un dimorphisme sexuel a été démontré au niveau des chromosomes chez les mammifères, le caryotype étant XX chez les femelles et XY chez les mâles. Le chromosome Y a un rôle dominant sur la différenciation des gonades, les individus XY et XXY développent des testicules et ont un phénotype mâle, tandis que ceux dont le caryotype est XX ou XXX développent des ovaires et un phénotype femelle (Jacobs \& Strong, 1959 ; Barr, 1966). Il a fallu attendre les années 1990 pour que le gène porté par le chromosome $Y$, déterminant pour la différenciation du testicule, appelé $S R Y$, soit identifié
(Berta et al., 1990; Sinclair et al., 1990). Beaucoup de travaux ont ensuite été menés pour comprendre son rôle et identifier les mécanismes de sa régulation ainsi que les réseaux de gènes qu'il contrôle (Koopman et al., 1991 ; Sekido et al., 2004 ; Sekido \& Lovell-Badge, 2008). Par contre, très peu d'études ont cherché à identifier un gène de déterminisme ovarien.

L'hypothèse d'un gène clé pour la détermination du sexe femelle a été formulée en 1993 par McElreavey et al. et par Goodfellow \& Lovell-Badge. Elle repose sur l'étude de patients atteints d'inversion sexuelle, hommes XX et femmes XY dont la survenue ne peut être expliquée par une simple absence / présence du gène $S R Y$. Ces auteurs ont proposé l'existence d'un facteur $\ll Z$ $Z$, produit par la gonade femelle $\mathrm{XX}$, qui activerait la différenciation ovarienne et inhiberait celle du testicule. Le facteur mâle SRY et certaines de ses cibles inhiberait cette cascade femelle initiée par Z. On aurait donc dans les deux sexes des facteurs inducteurs qui contrôleraient la différenciation de la gonade dans l'un et des facteurs inhibiteurs qui la réprimeraient dans l'autre. Certains facteurs pouvant agir simultanément sur les deux voies mâle et femelle, la notion de « balance des sexes » ou «bataille des sexes » est apparue (Kim \& Capel, 2006 ; Sinclair \& Smith, 2009 ; Veitia, 2010). La gonade indifférenciée du foetus de mammifères est donc capable de se différencier en ovaire ou testicule en fonction de l'expression de quelques gènes majeurs spécifiques de chaque sexe. Une altération dans l'expression de ces gènes va entraîner des pathologies d'inversion sexuelle ou aboutir à des cas d'infertilité ou encore être responsable de cancers ovariens.

Les progrès récents de la génétique chez la souris ainsi que l'utilisation des outils de transcriptomique et d'immunoprécipation de chromatine appliqués à plusieurs modèles animaux ont permis de montrer que la différenciation de l'ovaire est activement contrôlée par plusieurs réseaux de gènes et n'a rien d'un phénomène passif. Ceux-ci contrôlent toutes les étapes de la différenciation ovarienne, à savoir la formation de la gonade bipotentielle, la différenciation des cellules somatiques (folliculaires ou de granulosa, ainsi que les cellules stéroïdogènes), l'initiation de la méiose des ovogonies et la formation des follicules primordiaux, véritable réserve ovarienne qui se forme pendant la vie fotale chez la plupart des mammifères et perdurera durant toute la vie reproductive.

\section{De la formation des crêtes génitales vers la gonade indifférenciée}

Chez les mammifères, les crêtes génitales se forment très précocement pendant la vie fotale (dès 4 semaines 
Tableau 1. Effet de l'invalidation de gènes intervenant dans la mise en place de la gonade chez la souris.

\begin{tabular}{|c|c|c|c|}
\hline Nom du gène & Type de protéine & Effet de l'invalidation chez la souris & Références \\
\hline Lhx9 & Facteur de transcription & Absence de formation des crêtes génitales & Birk et al. $(2000)$ \\
\hline Lim1 & Facteur de transcription & Absence de formation des crêtes génitales & Shawlot et al. $(1995)$ \\
\hline Emx2 & Facteur de transcription & Absence de formation des gonades indifférenciées & Miyamoto et al. $(1997)$ \\
\hline Wt1 & Facteur de transcription & Dégénérescence des crêtes génitales néoformées & Kreidberg et al. $(1993)$ \\
\hline Sf1 & Récepteur nucléaire & Dégénérescence des crêtes génitales néoformées & $\begin{array}{c}\text { Luo } \text { et al. }(1994) \\
\text { Sadovsky et al. }(1995)\end{array}$ \\
\hline M33 & Facteur de transcription & Retard de la formation des gonades indifférenciées & Katoh-Fukui et al. $(1998)$ \\
\hline Pod1 & Facteur de transcription & Hypoplasie des gonades indifférenciées & Cui et al. $(2004)$ \\
\hline Smoc1 & $\begin{array}{c}\text { Protéine de la matrice } \\
\text { extracellulaire }\end{array}$ & $\begin{array}{c}\text { Défaut de différenciation et absence du maintien des } \\
\text { gonades indifférenciées }\end{array}$ & Pazin et al. (2009) \\
\hline
\end{tabular}

chez l'humain, 9 jours post-conception (jpc) chez la souris et vers $23-24$ jpc chez l'ovin). Les crêtes génitales constituent l'ébauche gonadique primitive. Sur la face ventro-médiane du mésonéphros, la prolifération des cellules de l'épithélium cœlomique et l'épaississement du mésenchyme sous-jacent conduisent à la formation des crêtes génitales. Les signaux contrôlant cet épaississement restent inconnus; en revanche, de nombreux gènes ont été décrits comme ayant un rôle dans le maintien et la croissance des crêtes génitales (Brennan \& Capel, 2004). L'invalidation de ces gènes conduit soit à une agénésie (absence de formation) soit à une dégénérescence des gonades. Après la colonisation des crêtes génitales par les cellules germinales primordiales, on parle de gonades indifférenciées ou bipotentielles. Chez les mammifères, les gonades sont composées de deux types cellulaires somatiques en plus des cellules germinales: les cellules de soutien (qui seront à l'origine des cellules de Sertoli chez le mâle et des cellules folliculaires (ou de granulosa) chez la femelle et les cellules stéroïdogènes (qui donneront les cellules de Leydig chez le mâle et les cellules de la thèque chez la femelle (Swain \& Lovell-Badge, 1999 ; Capel, 2000). L'effet de l'invalidation des gènes (décrits cidessous) sur le développement gonadique est récapitulé dans le tableau 1.

\section{- Les gènes à homéoboîte $(\operatorname{Lhx} 9, \operatorname{Lim} 1$ et $E m \times 2)$}

Le gène Lhx9 (Lim Homeobox9) code pour un facteur de transcription qui est exprimé très précocement dans les crêtes génitales : à 9,5 jpc chez la souris (Birk et al., 2000). Son invalidation chez la souris entraîne un défaut de prolifération de l'épithélium colomique, ce qui conduit à l'absence de formation des gonades indifférenciées
(Birk et al., 2000). De même que l'invalidation de Lim1, un autre facteur de transcription (appelé aussi $L h x 1$ ) conduit également à l'absence de formation des gonades indifférenciées (Shawlot et al., 1995).

Chez la souris, l'invalidation de Emx2 (Empty spiracles homeobox gene 2) empêche la formation des gonades (Miyamoto et al., 1997). Cette étude montre qu'Emx2 intervient dans la prolifération et dans le maintien des cellules de la gonade indifférenciée. Emx2 est le seul gène impliqué dans la formation des gonades qui ne soit pas relié à $S f 1$.

\section{- Le facteur Wt1}

Le gène Wt1 (Wilms' tumor suppressor) code pour un facteur de transcription à doigts de zinc. Il se fixe à l'ADN pour contrôler la transcription de gènes impliqués dans différents processus : la prolifération, la différenciation et l'apoptose (Menke et al., 1998). Cette protéine possède 24 isoformes qui peuvent être regroupées en deux familles : les isoformes qui ont les acides aminés lysine-thréonine-sérine entre les doigts de zinc 3 et $4(+\mathrm{KTS})$ et celles qui ne les ont pas (-KTS). La présence ou l'absence de cette séquence KTS définit la capacité de Wt1 à se fixer à l'ADN (-KTS) ou à l'ARN (+KTS) (Larsson et al., 1995). Chez la souris et l'homme, Wt1 est exprimé dès les premiers stades de formation des crêtes génitales et son expression est maintenue après la différenciation sexuelle des gonades dans les cellules de Sertoli chez le mâle et dans les cellules de la granulosa chez la femelle. Chez la souris, l'invalidation de $W t 1$ comme celle de $S f 1$ ne perturbe pas la formation des crêtes génitales, en revanche cellesci dégénèrent à 11,5 jpc par apoptose (Kreidberg et al., 1993). L'isoforme Wt1 (+KTS) est responsable de la 
différenciation des crêtes génitales ; par contre, l'isoforme (-KTS) joue un rôle dans la différenciation testiculaire (Hammes et al., 2001). Wt1 (-KTS) coopère avec la protéine Lhx9 pour activer l'expression de Sf1 (Wilhelm et al., 2002), ce qui expliquerait que l'invalidation de $W t 1$ ou de $S f 1$ aboutisse au même phénotype. Toutefois, les souris invalidées pour Wt1 expriment toujours $S f 1$ mais à des niveaux plus faibles que chez les souris sauvages, insuffisants pour le maintien des crêtes génitales (Hanley et al., 1999).

\section{- Le récepteur Sf1 ou NR5A1}

Sf1 ou NR5A1 (Steroidegenic factor 1) est un récepteur nucléaire dont le ligand n'a pas encore été identifié. Sf1, en plus de son rôle dans la formation des gonades, contrôle la synthèse de nombreuses hormones stéroïdiennes au cours du développement embryonnaire, d'où sa localisation dans de nombreux tissus ayant une activité endocrine : les gonades, les glandes surrénales, l'hypophyse et l'hypothalamus (Ingraham et al., 1994 ; Ikeda et al., 1995 ; Luo et al., 1995). Chez la souris, Sf1 est exprimé jusqu'à 12 jpc dans les gonades mâles et femelles. Puis, au delà de ce stade, ce gène possède une expression dimorphique mâle/femelle : dans le testicule, il est exprimé dans les cellules somatiques jusqu'à 18,5 jpc alors que dans l'ovaire, son expression ne réapparaîtra qu'à 18,5 jpc. $S f 1$ ne semble pas requis pour la formation des crêtes génitales mais est indispensable pour le maintien et la différenciation de la gonade. En effet, chez la souris, l'invalidation de $S f 1$ ne perturbe pas la formation des gonades mais cellesci dégénèrent par apoptose au delà de 11,5 jpc (Luo et al., 1994 ; Sadovsky et al., 1995). Chez la souris, Sf1 est également impliqué dans la détermination sexuelle des gonades. De fait, $S f 1$ joue un rôle dans la masculinisation de la gonade indifférenciée en agissant comme cofacteur pour induire l'expression de Sox 9 (Sekido et al., 2008) et de l'AMH (Arango et al., 1999). Une nouvelle étude vient de démontrer le rôle de $S f 1$ dans la différenciation de l'ovaire en activant l'expression de Wnt4 et Foxl2 (Combes et al., 2010).

\section{- Le facteur M33 ou CBX2}

Le gène M33 (appelé aussi CBX2 Chromobox homolog 2) est un orthologue d'un gène polycomb de la drosophile. Ces gènes polycomb sont connus pour réprimer l'expression des gènes Hox au cours du développement (en induisant la condensation de la chromatine) et pour réguler la prolifération cellulaire, comme M33 (Coré et al., 2004). L'invalidation de M33 chez la souris ne perturbe pas la formation des crêtes génitales mais induit un retard dans la formation des gonades (Katoh-Fukui et al., 1998).

\section{- Le facteur Pod1}

Pod1 est un facteur de transcription appartenant à la famille des bHLH (basic helix-loop-helix). L'invalidation de Pod1 chez les souris conduit à des défauts au niveau des reins, des muscles, de la rate et ces souris mutantes meurent à la naissance à cause de problèmes respiratoires (Quaggin et al., 1999 ; Lu et al., 2000, 2002). Une étude plus récente montre que Pod1 est exprimé dans les crêtes génitales à partir de 11 jpc (Cui et al., 2004). L'invalidation de Pod1 chez la souris provoque une hypoplasie des gonades (Cui et al., 2004). En effet, les gonades indifférenciées ont une morphologie anormale, elles sont petites et ont une surface irrégulière, comparées aux gonades de souris $\operatorname{Pod} 1^{+/+}$. Les défauts de développement des gonades pourraient provenir du fait que l'invalidation de Pod1 perturbe l'expression de $S f 1$. En effet, dans les gonades Pod1 ${ }^{-1-}$, l'expression de Sf1 est augmentée (Cui et al., 2004). Pod1 semble donc être nécessaire à l'expression correcte de $S f 1$ afin de permettre le maintien et un développement normal des gonades indifférenciées.

\section{- Les protéines Smoc}

Récemment deux nouvelles protéines de la matrice extracellulaire ont été identifiées, il s'agit de Smoc1 ( $S P A R C$ related modular calcium binding 1) et Smoc2 ( $S P A R C$ related modular calcium binding 2). Ces protéines appartiennent à la famille des protéines SPARC (Secreted acidic cysteine rich glycoprotein). Les protéines Smoc1 et Smoc2 ont un rôle dans la croissance, la prolifération et la migration. Smoc2 est uniquement exprimé dans les testicules (Pazin et al., 2009). En revanche, Smoc1 est exprimé dans les gonades indifférenciées dès 10,5 jpc (Pazin et al., 2009). À partir de $12,5 \mathrm{jpc}$, Smoc1 est exprimé de manière dimorphique mâle/femelle: l'expression de Smoc1 persiste dans les cellules de Sertoli alors qu'elle n'est plus visible dans l'ovaire (Pazin et al., 2009). Les souris invalidées soit pour $W t 1$ soit pour Sf1 ont une expression réduite de $S m o c 1$, ce qui indique que $S m o c 1$ est en aval de ces gènes mais à l'heure actuelle aucune donnée ne permet de savoir si Wt1 et/ou Sf1 contrôlent directement ou indirectement l'expression de Smoc1. Il semblerait que Smoc1 soit impliqué dans la différenciation et le maintien des cellules des gonades indifférenciées. 


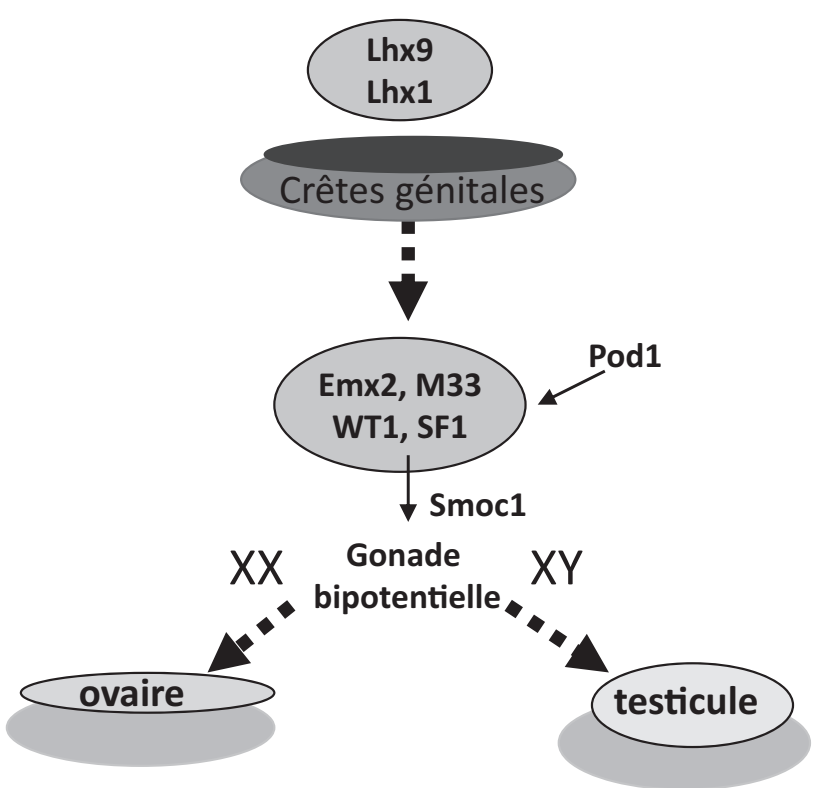

Fig. 1. Cascade des événements conduisant à la formation des gonades. Plusieurs gènes ont été identifiés, grâce à leur invalidation, comme nécessaires à la formation des crêtes génitales, puis des gonades indifférenciées. Sous l'action de quelques gènes à expression sexe-spécifique, la différenciation des cellules somatiques des gonades va être initiée et aboutir au développement de gonades femelles (ovaire) ou mâles (testicule).

Dès que les crêtes génitales sont formées, elles sont colonisées par les cellules germinales primordiales (vers 10,5 jpc chez la souris et $23-24$ jpc chez l'ovin). Cette première étape est nécessaire à la formation de gonades bipotentielles ou indifférenciées. Dans une deuxième étape, la mise en route de plusieurs cascades géniques va induire la différenciation des gonades indifférenciées soit en ovaire soit en testicule. Un résumé de ces étapes est présenté dans la figure 1.

\section{Différenciation des cellules somatiques ovariennes}

Les individus XX atteints d'inversion sexuelle de type mâle XX sans SRY sont censés être porteurs d'une mutation inactivant le gène $Z$. Il existe des individus de ce type dans plusieurs espèces de mammifères dont le porc, le chien, la chèvre et l'Homme (Vaiman \& Pailhoux, 2000 ; Vigier et al., 2001 ; Kim et al., 2010a ; Bigliardi et al., 2011). La chèvre a été très étudiée et un locus appelé PIS, pour Polled Intersex Syndrome, a été identifié comme responsable de cette inversion sexuelle. La délétion de ce locus entraîne l'absence de cornes dans les deux sexes à l'état hétérozygote, et une inversion sexuelle uniquement chez les femelles, à l'état homozygote (Vigier et al., 2001). La mutation responsable du syndrome PIS est une délétion d'environ 12 kilobases localisée à 300 kilobases en amont d'un gène dénommé FOXL2 (Forkhead box family $L$ number 2). Des études génétiques de clonage positionnel ont montré que le gène FOXL2, situé sur le chromosome humain $3 \mathrm{q} 23$, est impliqué dans le syndrome de Blepharophimosis-Ptosis-Epicanthus inversus (BPES) (Crisponi et al., 2001). Le locus PIS (1q43 chez la chèvre) et le locus BPES (3q23 chez l'Homme) sont localisés dans une région homologue de $100 \mathrm{~kb}$ (Schibler et al., 2000). Les mutations hétérozygotes du gène FOXL2 dans l'espèce humaine conduisent à une insuffisance ovarienne et une infertilité chez les femmes atteintes de BPES de type I (De Baere et al., 2002).

\section{- Le facteur de transcription FOXL2}

Dans les gonades femelles de ruminants, la perte de fonction de FOXL2 entraîne très précocement : (i) la déféminisation de la gonade XX avec perte de l'expression de l'aromatase et donc absence des œstrogènes et (ii) la masculinisation de celle-ci par surexpression du facteur mâle SOX9 entraînant la différenciation des cellules de Sertoli et l'expression de l'hormone anti-Müllerienne qui va faire régresser les canaux de Müller (Pannetier \& Pailhoux, 2010). On aura donc, dans cette espèce, une masculinisation complète des gonades et du tractus génital externe et développement d'un phénotype mâle chez des individus $\mathrm{XX}$ porteurs d'une mutation régulatrice inactivant le gène FOXL2.

Chez l'Homme, le syndrome BPES (perte d'un allèle de FOXL2) conduit à un phénotype anormal au niveau des paupières associé à un dysfonctionnement ovarien (ménopause précoce) mais pas à une inversion sexuelle. De plus, il n'a pas été retrouvé de mutations dans le gène FOXL2 de plusieurs patients atteints d'inversion sexuelle de type homme XX (De Baere et al., 2002).

L'invalidation du gène Foxl2 chez les souris XX n'entraîne pas d'inversion sexuelle, celles-ci ont un phénotype femelle mais sont stériles (Schmidt et al., 2004 ; Uda et al., 2004). Les ovaires des souris Foxl2 $^{-1}$ sont petits, sévèrement désorganisés et les follicules primordiaux ne se forment pas. L'invalidation ciblée du gène Foxl2 dans les cellules folliculaires adultes montre que chez ces animaux, les cellules somatiques de l'ovaire (cellules folliculaires) se mettent à exprimer le gène mâle Sox 9 et se transdifférencient en cellules de Sertoli 
(Uhlenhaut et al., 2009). La structure de la gonade ressemble alors, trois semaines après l'induction de la délétion de Foxl2, à un testicule avec l'apparition de structures ressemblant à des tubes séminifères. Une étude fine de la cinétique de transdifférenciation montre que les expressions des facteurs FOXL2 et SOX9 sont mutuellement exclusives. Il a été également montré que la sur-expression de Foxl2 dans des cellules de Sertoli $\mathrm{XY}$ induisait une désorganisation des tubes séminifères et le développement d'une gonade de type ovotestis (Ottolenghi et al., 2007). Ce phénomène d'exclusion mutuelle au sein des cellules somatiques des gonades renvoie au mécanisme de programmation initiale de la gonade où les deux déterminants clés (FOXL2 pour l'ovaire et SOX9 pour le testicule) s'inhibent l'un l'autre, directement ou indirectement, aboutissant à deux états alternatifs : mâle et femelle. Il reste à déterminer si l'expression de FOXL2 dans le testicule est réprimée par SRY ou SOX9 ou par les deux.

Les oestrogènes sont des acteurs majeurs de la différenciation ovarienne. Ils sont capables d'induire des inversions sexuelles de type mâle vers femelle chez de nombreux vertébrés (poissons, reptiles et oiseaux) et leur inhibition chez les femelles de ces différents phyla conduit à l'apparition de phénotypes mâles chez des individus génétiquement femelles (Smith et al., 2008b ; Vizziano-Cantonnet et al., 2008 ; Nakamura, 2010). Chez les mammifères, il existe des différences quant à la production d'œstrogènes par l'ovaire au cours de la période foetale. La souris, par exemple, n'en produit pas pendant la phase de différenciation précoce à l'inverse des ruminants et de l'Homme (Mauléon et al., 1977 ; George \& Wilson, 1978 ; Payen et al., 1996). Cette production d'œstrogènes par l'ovaire fotal est positivement régulée par FOXL2 chez les ruminants (Pannetier et al., 2006). On peut donc concevoir une boucle de régulation dans laquelle FOXL2 augmente l'expression de l'aromatase et la production des œestrogènes, lesquels contrôlent l'expression de FOXL2 via les récepteurs ESR.

Il a été montré par ailleurs que Foxl2 et les récepteurs des œestrogènes (Esr1/2) étaient capables d'interagir pour réprimer l'expression du facteur mâle Sox9 (via la séquence activatrice appelée TESCO) dans l'ovaire adulte (Uhlenhaut et al., 2009).

Le phénotype d'inversion sexuelle par inactivation de FOXL2 apparaît plus précocement chez la chèvre (PIS syndrome) que chez la souris XX (KO Foxl2). Cette différence de phénotype entre les espèces est probablement en relation avec le décalage de production des œestrogènes entre les ruminants et les rongeurs. Sans les œestrogènes, Foxl2 perd une boucle de régulation positive et n'est plus le facteur clé pour réprimer efficacement l'expression de gènes mâles dans la gonade femelle des rongeurs. On peut alors imaginer qu'une autre voie de signalisation (Rpo1, Wnt4 et voie de la $\beta$-caténine) devienne prépondérante pour inhiber l'expression de Sox9 au cours du développement précoce chez la souris. Par ailleurs, FOXL2 chez les mammifères non rongeurs semble avoir un rôle inhibiteur sur un autre gène mâle que $S O X 9$, à savoir $D M R T 1$ qui, lui, active $S O X 9$. L'analyse transcriptomique haut débit de gonades femelles inactivées ou non pour le gène FOXL2 chez la chèvre devrait permettre d'apporter des réponses à ces questions.

Plusieurs gènes cibles de FOXL2 ont été identifiés par des analyses transcriptomiques entre lignées cellulaires surexprimant ou non Foxl2 ainsi qu'entre des souris inactivées ou non pour Foxl2 (Batista et al., 2007 ; Garcia-Ortiz et al., 2009). Comme attendu, il a été montré que FOXL2 régule positivement des gènes ovariens (Fst, Dax1) et négativement des gènes testiculaires $(\operatorname{Sox} 9, D h h, \operatorname{Inh} b b, A m h)$. FOXL2 intervient dans de nombreuses fonctions cellulaires telles que celles contrôlant les interactions cellulaires, le métabolisme du glucose et du cholestérol, la synthèse des protéines. Une étude récente a également montré que FOXL2 module les régulateurs du cycle cellulaire et tend à induire un arrêt en phase G1, protégeant ainsi les cellules de granulosa du stress oxydatif (Benayoun et al., 2011). Ces données étayent l'idée que FOXL2 joue un rôle majeur dans l'homéostasie des cellules de granulosa, contrôlant de ce fait le vieillissement ovarien ou la tumorigénèse de ces cellules. Par ailleurs, il a été montré que les niveaux d'expression de FOXL2 dans une série de tumeurs de l'ovaire de la granulosa de type juvénile(OGCTs) sont fortement réduits. Plus récemment, le séquençage du transcriptome de plusieurs OGCTs de type adulte a permis l'identification de la mutation somatique récurrente au sein du gène FOXL2 p.Cys134Trp (C134W). La présence de cette mutation a été confirmée dans $95 \%$ des OGCTs adultes, $21 \%$ des tumeurs à cellules thécales et dans $10 \%$ des OGCTs juvéniles (ce qui est probablement dû à une mauvaise classification). Nous avons suggéré que FOXL2 pourrait agir comme un gène suppresseur de tumeur. Ceci est en accord avec le fait que d'autres facteurs de transcription Forkhead ont déjà été impliqués dans l'étiologie du cancer (Benayoun et al., 2010). Dans une étude récente, il a été montré que la protéine FOXL2 normale induit la mort par apoptose des cellules de la granulosa alors que le mutant $\mathrm{C} 134 \mathrm{~W}$ a une activité pro-apototique très faible. La réponse apoptotique induite par FOXL2 semble dépendante de la caspase 8, BID et BAK (Benayoun et al., 2010 ; Jamieson et al., 2010 ; Kim et al., 2010b, 2011 ; Al-Agha et al., 2011 ; 


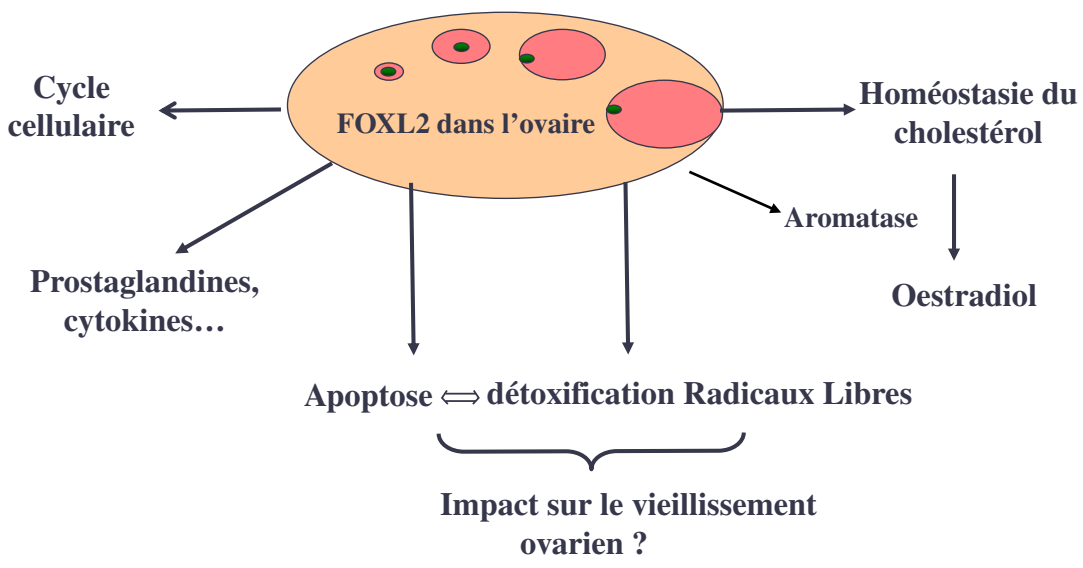

Fig. 2. FOXL2, chef d'orchestre de la différenciation ovarienne. Le facteur FOXL2 intervient dans de multiples processus impliqués dans la différenciation et la fonction ovarienne. Il contribue à l'identité femelle des cellules de granulosa, contrôle leur prolifération, leur fonctionnement et leur vieillissement. Il semble également impliqué dans leur cancérisation.

Hes et al., 2011). Les différents rôles de la protéine FOXL2 au cours de la différenciation et de la fonction ovarienne sont schématisés dans la figure 2 .

\section{- Rspo1, Wnt4 et la voie de la B-caténine}

La voie de signalisation intracellulaire Wnt/ $\beta$-caténine est très conservée depuis le nématode jusqu'à l'Homme et contrôle un très grand nombre de processus développementaux. Chez la souris, Wnt4 (wingless-type MMTV integration site family, member 4) est un gène exprimé dans les gonades mâle et femelle avant 11,5 jpc. À partir de 11,5 jpc, Wnt4 est exprimé uniquement chez la femelle par les cellules somatiques de l'ovaire. L'invalidation de ce gène chez la souris entraîne une masculinisation partielle des gonades XX et du tractus génital (Vainio et al., 1999). Les souris XX $W_{n} 4^{-l-}$ ont une vascularisation typiquement mâle et des cellules de Leydig se différencient. Cependant, bien que l'expression de Sox9 soit initiée, celle-ci n'est pas maintenue et il n'y a pas différenciation de cellules de Sertoli. De plus, une absence d'expression de la follistatine et une apoptose massive des ovocytes sont observées quelques jours avant la naissance (Yao et al., 2004). Le gène de la follistatine est donc une cible de WNT4. Dans des conditions normales, la follistatine inhibe la formation du vaisseau coelomique dans la gonade XX murine. Ce vaisseau apparaît spécifiquement lors de la formation du testicule dès $12,5 \mathrm{jpc}$ chez la souris (Jeays-Ward et al., 2003 ; Yao et al., 2004). Par ailleurs, il a été montré que WNT4 a un effet antagoniste sur la voie FGF9/FGFR2 et donc indirectement peut interférer avec le maintien de l'expression de SOX9 (Kim \& Capel, 2006). Une mutation perte de fonction de WNT4 a été rapportée chez un patient XX atteint d'inversion sexuelle femelle vers mâle (Bernard \& Harley, 2007). Cela suggère qu'il existerait un antagonisme entre deux voies de signalisation sexe-spécifiques, celle de FGF9 orientant vers le développement testiculaire et celle de WNT4 vers le développement ovarien (DiNapoli \& Capel, 2008). En 2006, un nouvel acteur clé de la différenciation ovarienne a été découvert par une équipe italienne, il s'agit du gène $R$-spondin 1 (RSPO1) (Parma et al., 2006). L'analyse génétique de cas familiaux d'inversion sexuelle de type XX femelle vers mâle a montré qu'une mutation homozygote perte de fonction de $R S P O 1$, gène impliqué dans la voie de signalisation $W N T$, engendrait une masculinisation de la gonade des patients XX. Or la signalisation initiée par WNT4 et R-spondine 1 conduit à la stabilisation de la forme canonique de la $\beta$-caténine (Chassot et al., 2008). Chez la souris, Rspo1 est exprimé dans toute la gonade XX à 11,5 jpc. Les souris invalidées pour $R$ spo 1 présentent une inversion sexuelle partielle de type femelle vers mâle XX, similaire au phénotype des souris invalidées pour le gène $W n t 4$. Le phénotype mutant $R$ spo $1^{-1-}$ peut être sauvé par la surexpression de $\beta$-caténine (Chassot et al., 2008). Rspo1 et Wnt4 joueraient donc un rôle important dans la détermination du sexe femelle et la différenciation des gonades en ovaires en assurant un niveau suffisant de $\beta$-caténine dans les cellules somatiques ovariennes. WNT4 et RSPO1 sont localisés sur la même région chromosomique et une duplication de celle-ci a été retrouvée chez un patient XY atteint d'inversion sexuelle mâle vers femelle (Jordan et al., 2001). Récemment, il a été montré que l'expression conditionnelle de $\beta$-caténine conduit au développement d'un ovaire chez un foetus XY (Maatouk et al., 2008). De plus, dans les gonades de souris XX 
$W n t_{4}^{-l-}$, Rspo1 est toujours exprimé, alors que dans les gonades XX Rspo1 ${ }^{-1-}$, Wnt4 n'est plus exprimé (Chassot et al., 2008). L'expression de Wnt4 est donc sous le contrôle de Rspo1. De plus, les protéines RSPO1 et WNT4 activent toutes les deux la voie de signalisation de la $\beta$-caténine dans l'ovaire et l'invalidation de leur gène respectif induit une masculinisation de la gonade XX. Au cours de la différenciation ovarienne, l'activation de la voie de signalisation $\beta$-caténine canonique entraîne la dégradation de SOX9, empêchant qu'elle s'auto-active ou active d'autres gènes impliqués dans la différenciation testiculaire, tels que Fgf9. La $\beta$-caténine est donc un facteur pro-ovarien et anti-testiculaire, qui intervient également dans l'engagement des cellules germinales vers l'entrée en méiose.

\section{Différenciation des cellules germinales femelles}

\section{- La méiose}

À leur arrivée dans les gonades, les cellules germinales continuent de proliférer activement. Dans l'ovaire (13,5 jpc chez la souris et à partir de 50-55 jpc chez la brebis), les cellules germinales stoppent leur multiplication mitotique pour entrer en méiose, plus exactement en prophase I de méiose. La méiose est initiée de façon synchrone (chez les rongeurs) ou asynchrone (humain : Skrzypczak et al., 1981, ovin : Sawyer et al., 2002) dans les ovogonies et s'arrête avant la naissance (sauf chez le lapin où la prophase I de méiose s'arrête quelques jours après la naissance). La prophase I est divisée en cinq étapes (leptotène, zygotène, pachytène, diplotène, diacinèse) caractérisées par des modifications au niveau des chromosomes. Les quatre premières étapes ont lieu pendant la vie foetale, puis les cellules germinales se bloquent au stade diplotène. La dernière étape (diacinèse) reprendra à la puberté. La méiose sera finalement achevée lors de la fécondation de l'ovule. Après l'entrée en méiose, les ovogonies sont renommées sous le terme d'ovocytes I. Le blocage des ovocytes en fin de prophase I est spécifique de la femelle.

Chez le mâle, la méiose ne débute qu'après la naissance (de 5-8 jours post-partum chez la souris à environ 8 mois chez le bélier).

\section{- Initiation de la prophase I de méiose}

Différentes études utilisant la technologie des microréseaux ont cherché à isoler des gènes intervenant dans la méiose en comparant, par exemple, l'activité transcriptionnelle d'ovaires avec ou sans cellules germinales (Nef et al., 2005) ou d'ovaires fotaux à différents stades de développement (Baillet et al., 2008). Un des premiers facteurs nécessaires pour engager les cellules germinales vers le processus de méiose est DazL (Deleted in azoospermia-like). DAZL est une RNA-binding protein exprimée à partir de 11,5 jpc par les cellules germinales (post-migration) de souris mâles et femelles. L'inactivation de Dazl conduit à une infertilité des mâles et des femelles, à une absence d'expression des gènes impliqués en début de prophase I, dont Stra8 (Stimulated by retinoic acid gene 8), le gène qui initie la prophase I (Lin et al., 2008). L'expression précoce de $\operatorname{Dazl}$ (en amont de celle de Stra8) permettrait aux cellules germinales d'être « compétentes » pour entrer en méiose. L'invalidation du gène Dazl chez la souris a aussi montré un rôle de celui-ci plus en aval dans le contrôle de la stabilité du transcrit Sycp3 (Synaptonemal complex protein3) et sa traduction (Reynolds et al., 2007).

Une fois les cellules germinales devenues « compétentes » grâce à l'action de Dazl, plusieurs études ont montré que l'entrée en méiose des cellules germinales femelles de souris est un processus dépendant de l'acide rétinoïque (AR), métabolite actif de la vitamine A, par l'action successive de la rétinol-déshydrogénase puis de la rétinal-déshydrogénase. (Bowles et al., 2006 ; Koubova et al., 2006). L'induction de la méiose par AR a également été démontrée chez d'autres espèces comme le rat ( $\mathrm{Li} \&$ Clagett-Dame, 2009), l'Homme (Le Bouffant et al., 2010), le poulet et les amphibiens (Smith et al., 2008a; Wallacides et al., 2009). Chez la souris, l'AR est synthétisé dans le mésonéphros et, selon l'hypothèse actuelle, il diffuserait depuis le mésonéphros vers la gonade adjacente (Bowles et al., 2006). Des concentrations élevées d'AR sont responsables de l'induction de la méiose dans l'ovaire fotal en développement (Menke \& Page, 2002 ; Bowles et al., 2006 ; Koubova et al., 2006) et l'inhibition chimique des récepteurs de l'AR (RAR, de type $\alpha, \beta$ ou $\gamma$ ) entraîne une inhibition de Stra8 dans des cultures ex vivo de gonades foetales femelles de souris (Koubova et al., 2006). Dans un modèle de rat déficient en vitamine A (late VAD rat), la plupart des cellules germinales n'entrent pas en méiose (Li \& Clagett-Dame, 2009). L'ensemble de ces résultats montre le rôle indispensable de l'acide rétinoïque au moment de l'initiation de méiose. L'acide rétinoïque se fixe sur RAR et cet ensemble récepteur-ligand active un de ses gènes cibles, Stra8, en se fixant sur les éléments régulateurs RARE (Oulad-Abdelgnami et al., 1996). La fonction moléculaire de la protéine STRA8 n'est pas connue et cette 
protéine ne possède aucune homologie avec d'autres protéines connues. Stra8 est requis pour la synthèse préméiotique d'ADN (réplication de l'ADN des cellules germinales au stade pré-leptotène), l'initiation de la méiose et la progression de la méiose dans les cellules germinales. Chez la souris, son invalidation empêche les cellules germinales d'entrer en méiose (Baltus et al., 2006). Dans l'ovaire foetal, l'expression de Stra 8 est suivie par l'expression de gènes clés intervenant dans la méiose comme Sycp3 et Dmc1 (Menke et al., 2003).

A priori, on peut supposer que l'environnement de la gonade en AR est le même dans les deux sexes, bien que la méiose soit initiée uniquement chez la femelle pendant la vie fotale. Chez la souris mâle, il a été démontré que l'AR est dégradé via l'enzyme CYP26b1, produite par les cellules de Sertoli. C'est pourquoi il n'y aurait pas induction de Stra8 et donc pas d'entrée en méiose avant la puberté chez le mâle. De plus, dans la gonade fotale mâle, d'autre facteurs viennent empêcher les cellules germinales d'entrer en méiose comme FGF9 et Nanos2 (Suzuki et al., 2008 ; Bowles et al., 2010).

La régulation de l'initiation de la méiose, via l'AR, pourrait être différente selon les espèces. Dans l'ovaire fotal humain, l'expression d'ALDH1 (enzyme permettant la synthèse d'AR) est augmentée lorsque la méiose débute, tandis que celle de Cyp26B1 n'est pas modifiée. Le niveau d'expression de Cyp26B1 est, chez cette espèce, légèrement supérieur dans l'ovaire par rapport au testicule (Le Bouffant et al., 2010 ; Childs et al., 2011). Dans l'ovaire foetal murin, au moment de la méiose, l'expression d'ALDH1 est inchangée tandis que celle de Cyp26B1 diminue, empêchant la dégradation de l'AR. Plusieurs équipes émettent l'hypothèse selon laquelle l'ALDH1 contrôlerait le niveau d'AR dans l'ovaire foetal humain (Le Bouffant et al., 2010) et que l'ovaire foetal humain aurait la capacité intrinsèque de synthétiser l'AR (Childs et al., 2011).

Une étude récente vient cependant atténuer le rôle de l'AR provenant du mésonéphros comme inducteur de la méiose dans l'ovaire fotal murin (Kumar et al., 2011). L'expression de Stra 8 dans des ovaires foetaux de souris ALDH2 $2^{-1-}$ (souris dépourvues d'AR mais supplémentées via l'alimentation) n'est pas modifiée par l'absence de synthèse d'AR endogène. L'ovaire fotal de souris pourrait produire de l'acide rétinoïque en quantité suffisante pour induire Stra8. Ces auteurs suggèrent que l'AR synthétisé par le mésonéphros d'un embryon normal ne diffuse pas en quantité suffisante pour stimuler l'expression de Stra8 dans l'ovaire foetal (Kumar et al., 2011).

Reste à découvrir quel facteur contrôle l'expression sexe-spécifique des enzymes produisant l'acide rétinoïque dans les cellules somatiques de l'ovaire.
Une fois la méiose initiée par le gène Stra8, les cellules germinales femelles vont poursuivre la méiose avant d'être bloquées au stade diplotène de prophase I. Ces différentes étapes font intervenir des protéines spécifiques dont l'invalidation, chez la souris, n'a pas le même effet sur la progression de la méiose entre mâle et femelle (tableau 2). Chez le mâle, les invalidations de certains gènes (Sycp, Msh, Dmc1...) entraînent des blocages à différentes étapes de la prophase I (zygotène ou pachytène), et provoquent alors l'entrée en apoptose des cellules germinales, ce qui aboutit à une infertilité des souris. Chez la femelle, les phénotypes des souris mutantes peuvent être différents, de parfaitement fertiles à subfertiles ou totalement stériles. Il existe donc des mécanismes sexe-spécifiques du déroulement de la méiose.

\section{La formation des follicules}

La formation des follicules et la folliculogenèse basale (indépendante des hormones) ont lieu dans un ovaire organisé d'un point de vue morphologique (cortex et médulla). Les follicules se forment lorsque les ovocytes sont bloqués au stade diplotène de prophase I et cette formation de follicules a lieu pendant la période foetale (à partir de 14-15 semaines chez l'Homme et 75 jpc chez la brebis) ou quelques jours après la naissance $(2-5 \mathrm{j} p p$ chez la souris, $7-10 \mathrm{j} p p$ chez le lapin). La folliculogenèse est le processus par lequel plusieurs cellules somatiques (les précurseurs des cellules de la granulosa) vont entourer l'ovocyte formant alors un follicule, entité fonctionnelle de l'ovaire. Les follicules ainsi formés vont passer par plusieurs stades de différenciation: primordial, primaire, secondaire, tertiaire. La formation des follicules primordiaux résulte de la fragmentation des cordons ovigères, qui se déroule à l'interface medulla/ cortex de l'ovaire, puis s'étend vers l'épithélium de surface de l'ovaire. Ces follicules primordiaux sont constitués d'un ovocyte entouré par quelques cellules somatiques aplaties, les futures cellules de la granulosa. Des expériences d'invalidation de gènes chez la souris ont permis de mieux comprendre le rôle de certains gènes contrôlant la formation des follicules (tableau 3 ).

Les différentes étapes de maturation des follicules sont contrôlées par de nombreux facteurs et nécessitent un dialogue très précis entre l'ovocyte et les cellules somatiques qui l'entourent (références dans Edson et al., 2009). Deux types de régulation s'exercent sur la folliculogenèse: une régulation intra-folliculaire et une régulation inter-folliculaire. Les régulations intrafolliculaires se font via des facteurs de type paracrine (KL, FOXO3a, SOHLH1 et 2, BMP15, GDF9...) et coordonnent la croissance de l'ovocyte et des cellules 
Tableau 2. Principaux gènes intervenant en prophase I de méiose et effets de leurs invalidations chez les souris mâles et femelles.

\begin{tabular}{|c|c|c|c|c|c|}
\hline $\begin{array}{c}\text { Catégorie } \\
\text { de protéines }\end{array}$ & $\begin{array}{c}\text { Nom } \\
\text { du } \\
\text { gène }\end{array}$ & $\begin{array}{l}\text { Fonction lors } \\
\text { de la méiose }\end{array}$ & $\begin{array}{c}\text { Effet de } \\
\text { l'invalidation chez } \\
\text { le mâle }\end{array}$ & $\begin{array}{c}\text { Effet de } \\
\text { l'invalidation } \\
\text { chez la femelle }\end{array}$ & Références \\
\hline \multirow{3}{*}{$\begin{array}{l}\text { Protéines du } \\
\text { complexe } \\
\text { synaptonémal }\end{array}$} & Sycp1 & $\begin{array}{c}\text { Rôle dans l'appariement } \\
\text { des chromosomes homologues }\end{array}$ & $\begin{array}{c}\text { Stérile } \\
\text { (blocage en pachytène) }\end{array}$ & Stérile & de Vries et al. (2005) \\
\hline & Sycp3 & $\begin{array}{c}\text { Rôle dans l'appariement } \\
\text { des chromosomes homologues }\end{array}$ & $\begin{array}{c}\text { Stérile } \\
\text { (blocage en zygotène) }\end{array}$ & $\begin{array}{c}\text { Fertile } \\
\text { (aneuploïdie) }\end{array}$ & Yuan et al. (2002) \\
\hline & Syce2 & $\begin{array}{l}\text { Rôle dans la mise en place } \\
\text { du complexe synaptonémal }\end{array}$ & Stérile & Subfertile & $\begin{array}{l}\text { Bolcun-Filas } \\
\text { et al. }(2007)\end{array}$ \\
\hline \multirow{3}{*}{$\begin{array}{l}\text { Protéines } \\
\text { TEX }\end{array}$} & Tex11 & $\begin{array}{c}\text { Rôle dans l'appariement } \\
\text { des chromosomes homologues }\end{array}$ & Stérile & Subfertile & Adelman et al. (2008) \\
\hline & Tex14 & $\begin{array}{l}\text { Rôle dans la formation des ponts } \\
\text { qui relient les cellules germinales }\end{array}$ & Stérile & Fertile & $\begin{array}{l}\text { Greenbaum } \\
\text { et al. }(2006)\end{array}$ \\
\hline & Tex15 & $\begin{array}{c}\text { Rôle dans l'appariement } \\
\text { des chromosomes homologues }\end{array}$ & Stérile & Fertile & Yang et al. (2008) \\
\hline \multirow{4}{*}{$\begin{array}{l}\text { Protéine de } \\
\text { cassures } \\
\text { doubles brins } \\
\text { et réparations }\end{array}$} & Spo11 & $\begin{array}{c}\text { Rôle dans la cassure doubles } \\
\text { brins }\end{array}$ & Stérile & $\begin{array}{c}\text { Stérile } \\
\text { Perte des cellules } \\
\text { germinales }\end{array}$ & $\begin{array}{l}\text { Romanienko } \\
\text { et al. }(2000)\end{array}$ \\
\hline & Mei1 & $\begin{array}{c}\text { Rôle dans la cassure doubles } \\
\text { brins }\end{array}$ & Stérile & Stérile & Libby et al. (2002) \\
\hline & $D m c 1$ & $\begin{array}{c}\text { Rôle dans la fixation des } \\
\text { cassures doubles brins et de leur } \\
\text { réparation }\end{array}$ & Stérile & $\begin{array}{c}\text { Stérile } \\
\text { (blocage en } \\
\text { pachytène) }\end{array}$ & $\begin{array}{l}\text { Pittman et al. }(1998) \\
\text { Yoshida et al. (1998) }\end{array}$ \\
\hline & $\operatorname{Rad} 51$ & $\begin{array}{c}\text { Rôle dans la fixation } \\
\text { des cassures doubles brins et } \\
\text { de leur réparation (gonades) }\end{array}$ & Létal & Létal & Tsusuki et al. (1996) \\
\hline \multirow{5}{*}{$\begin{array}{l}\text { Protéines } \\
\text { MSH-MLH }\end{array}$} & $M_{4} 4$ & $\begin{array}{l}\text { Rôle dans la synapse entre } \\
\text { les chromosomes homologues }\end{array}$ & Stérile & $\begin{array}{c}\text { Stérile } \\
\text { Perte des cellules } \\
\text { germinales }\end{array}$ & Kneitz et al. (2000) \\
\hline & Msh5 & $\begin{array}{l}\text { Rôle dans la synapse entre } \\
\text { les chromosomes homologues }\end{array}$ & $\begin{array}{c}\text { Stérile } \\
\text { Perte des cellules } \\
\text { germinales }\end{array}$ & $\begin{array}{c}\text { Stérile } \\
\text { Perte des cellules } \\
\text { germinales }\end{array}$ & de Vries et al. (1999) \\
\hline & Mlh1 & $\begin{array}{l}\text { Rôle dans la réalisation } \\
\text { des crossing-over }\end{array}$ & $\begin{array}{c}\text { Stérile } \\
\text { Perte des cellules } \\
\text { germinales }\end{array}$ & $\begin{array}{c}\text { Stérile } \\
\text { Perte des cellules } \\
\text { germinales }\end{array}$ & Edelmann et al. (1996) \\
\hline & Mlh3 & $\begin{array}{l}\text { Rôle dans la réalisation } \\
\text { des crossing-over }\end{array}$ & $\begin{array}{c}\text { Stérile } \\
\text { Perte des cellules } \\
\text { germinales }\end{array}$ & $\begin{array}{c}\text { Stérile } \\
\text { Perte des cellules } \\
\text { germinales }\end{array}$ & Lipkin et al. (2002) \\
\hline & Pms2 & $\begin{array}{l}\text { Rôle dans la synapse entre } \\
\text { les chromosomes homologues }\end{array}$ & Stérile & Fertile & Baker et al. (1995) \\
\hline
\end{tabular}

de la granulosa. Les régulations inter-folliculaires permettent aux follicules qui se développent de moduler l'entrée en croissance des follicules primordiaux (via l'AMH par exemple).

\section{- La formation des follicules primordiaux}

\section{Le facteur FIGLA}

Le premier facteur de transcription découvert pour son rôle dans la formation des follicules est FIGLA ( Factor in the germline alpha). Il comporte un domaine HLH (helix loop helix). Il a été mis en évidence lors de l'identification des facteurs impliqués dans la transcription des gènes de la zone pellucide (Zp) (Liang et al., 1997). L'invalidation de ce gène conduit à une stérilité des souris femelles mais est sans conséquence sur la fertilité des souris mâles (Soyal et al., 2000). Les souris invalidées pour Figla possèdent des ovaires dépourvus de follicules primordiaux et quelques jours après la naissance, les cellules germinales ont toutes disparu. Le facteur 
Tableau 3. Récapitulatif des gènes intervenant au cours de la folliculogenèse.

\begin{tabular}{|c|c|c|c|c|}
\hline $\begin{array}{c}\text { Nom } \\
\text { du gène }\end{array}$ & $\begin{array}{c}\text { Localisation cellulaire } \\
\text { dans l'ovaire }\end{array}$ & $\begin{array}{l}\text { Effet de l'invalidation } \\
\text { chez la souris femelle }\end{array}$ & Rôle & Références \\
\hline Figla & Ovocytes en nids & $\begin{array}{l}\text { Infertile : absence de } \\
\text { primordiaux }\end{array}$ & $\begin{array}{c}\text { Formation du stock } \\
\text { de follicules primordiaux }\end{array}$ & Soyal et al. (2000) \\
\hline Fохоза & $\begin{array}{c}\text { Ovocytes } \\
\text { (primordiaux et } 1^{\text {aires })}\end{array}$ & $\begin{array}{l}\text { Infertile: activation de tous les } \\
\text { follicules primordiaux }\end{array}$ & $\begin{array}{c}\text { Maintien du stock de follicules } \\
\text { primordiaux }\end{array}$ & $\begin{array}{l}\text { Castrillon et al. (2003) } \\
\text { Liu et al. (2007) }\end{array}$ \\
\hline Amh & $\begin{array}{c}\text { Cellules de la granulosa } \\
\text { (follicule } 1^{\text {aire }} \text { jusqu'au } \\
\text { stade antral) }\end{array}$ & $\begin{array}{l}\text { Infertile à } 4 \text { mois : activation } \\
\text { de tous les primordiaux }\end{array}$ & $\begin{array}{c}\text { Maintien du stock de follicules } \\
\text { primordiaux }\end{array}$ & Durlinger et al. (1999) \\
\hline Kit $/ K L$ & $\begin{array}{c}\text { Kit: sur les ovocytes } \\
\text { (à tous les stades) } \\
\text { KL: cellules pré-granulosa } \\
\text { et granulosa }\end{array}$ & $\begin{array}{c}\text { Absence croissance follicules } \\
\text { primordiaux }\end{array}$ & $\begin{array}{c}\text { Transition follicules } \\
\text { primordiaux } / 1^{\text {aires }} \text { et } \\
\text { maturation des follicules } 2^{\text {aires }}\end{array}$ & $\begin{array}{l}\text { Horie et al. (1991) } \\
\text { Yoshida et al. (1997) }\end{array}$ \\
\hline Sohlh1 & $\begin{array}{c}\text { Ovocyte } \\
\text { (follicules primordiaux) }\end{array}$ & $\begin{array}{l}\text { Infertile : blocage au stade } \\
\text { follicule primordial }\end{array}$ & $\begin{array}{l}\text { Transition follicules } \\
\text { primordiaux- } 1^{\text {aires }}\end{array}$ & $\begin{array}{l}\text { Pangas et al. }(2006) \\
\text { Choi et al. }(2008)\end{array}$ \\
\hline Sohlh2 & $\begin{array}{c}\text { Ovocytes } \\
\text { (primordiaux et } 1^{\text {aires})}\end{array}$ & $\begin{array}{l}\text { Infertile : blocage au stade } \\
\quad \text { follicule primordial }\end{array}$ & $\begin{array}{l}\text { Transition follicules } \\
\text { primordiaux-1 }\end{array}$ & $\begin{array}{l}\text { Pangas et al. }(2006) \\
\text { Choi et al. }(2008)\end{array}$ \\
\hline $\operatorname{Lh} x 8$ & $\begin{array}{c}\text { Ovocytes } \\
\text { (à tous les stades) }\end{array}$ & $\begin{array}{l}\text { Infertile : blocage au stade } \\
\text { follicule primordial }\end{array}$ & $\begin{array}{l}\text { Transition follicules } \\
\text { primordiaux- } 1^{\text {aires }}\end{array}$ & Pangas et al. (2006) \\
\hline Nobox & $\begin{array}{c}\text { Ovocytes } \\
\text { (à tous les stades) }\end{array}$ & $\begin{array}{l}\text { Infertile : blocage au stade } \\
\text { follicule primordial }\end{array}$ & $\begin{array}{l}\text { Transition follicules } \\
\text { primordiaux-1 }{ }^{\text {aires }}\end{array}$ & Rajkovic et al. (2004) \\
\hline Foxl2 & Cellules de la granulosa & $\begin{array}{l}\text { Infertile : blocage au stade } \\
\text { follicule primordial }\end{array}$ & $\begin{array}{l}\text { Transition follicule } \\
\text { primordiaux-1 }\end{array}$ & $\begin{array}{l}\text { Schmidt et al. }(2004) \\
\text { Uda et al. }(2004)\end{array}$ \\
\hline Gdf9 & $\begin{array}{c}\text { Ovocytes de follicules } 1^{\text {aires }} \\
\text { et ovocytes ovulatoires }\end{array}$ & $\begin{array}{c}\text { Infertile : blocage } \\
\text { au stade follicule } 1^{\text {aire }}\end{array}$ & $\begin{array}{c}\text { Transition follicule } \\
1^{\text {aire }}-2^{\text {aire }}\end{array}$ & $\begin{array}{l}\text { Elvin et al. (1999) } \\
\text { Dong et al. }(1999)\end{array}$ \\
\hline Bmp15 & $\begin{array}{l}\text { Ovocytes de follicules } 1^{\text {aires }} \\
\text { et pré-ovulatoires }\end{array}$ & 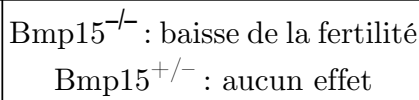 & $\begin{array}{c}\text { Transition follicule } \\
1^{\text {aire }}-2^{\text {aire }}\end{array}$ & Yoshino et al. (2006) \\
\hline
\end{tabular}

FIGLA, présent dans les ovocytes, intervient dans la formation du stock de follicules primordiaux mais contrôlerait également l'expression de plusieurs gènes, ceux nécessaires à la formation de la $\mathrm{Zp}$, ainsi que ceux impliqués dans la formation des follicules primordiaux, la fécondation ou le développement préimplantatoire comme Pou5f1 (POU-type homeodomain-containing DNA-binding protein, aussi nommé Oct4), Nlrp14 (NLR family, pyrin domain containing 14 ou NACHT), Dppa3 (Stella)) (Soyal et al., 2000 ; Joshi et al., 2007). La cascade moléculaire en aval de FIGLA n'est pas encore clairement établie. Chez la femme, le transcrit FIGLA est exprimé fortement à 19 semaines, période pendant laquelle les follicules primordiaux se forment (Bayne et al., 2004).

\section{Les facteurs SOHLH}

D'autres facteurs de transcription spécifiques des cellules germinales et à domaine LHL ont été identifiés pour avoir également un rôle essentiel dans la formation des follicules, il s'agit de SOHLH1 et SOHLH2 (spermatogenesis and oogenesis specific basic helixloop-helix 1 et 2). L'invalidation de ces gènes conduit à une absence de follicules primordiaux (Pangas et al., 2006 ; Choi et al., 2008) et les ovaires de ces souris mutantes $\left(\right.$ Sohlh $1^{--}$et Sohlh $2^{--}$) présentent une altération de l'expression d'autres facteurs de transcription ayant un rôle dans la folliculogenèse basale comme Lhx8 (lim homeobox protein 8), Pou5f1, Nobox (newborn ovary homeobox), et Figla (Rajkovic et al., 2004 ; Choi et al., 2008). Il existe des boucles de régulation entre ces facteurs de transcription SOHLH : les ovaires des souris Sohlh $1^{-1-}$ présentent une baisse d'expression de Sohlh2 et inversement.

\section{Les neutrophines}

Quatre des cinq neutrophines connues à ce jour sont exprimées dans l'ovaire (NGF, nerve growth factor; 
BDNF, brain-derived neurotrophic factor; NFT3 et NFT5, neurotrophines 3 et 5) ainsi que leurs récepteurs (Dissen et al., 1995). NGF est exprimé dans les cellules germinales et les cellules de granulosa juste avant la formation des follicules. Son invalidation réduit de façon drastique le nombre de follicules primaires dans les ovaires de ces souris mutantes ainsi que la prolifération des cellules somatiques (Dissen et al., 2001) suggérant un rôle important du signal NGF pour la différenciation des cellules de pré-granulosa en cellules de granulosa cuboïdales.

\section{La voie Notch}

Chez la souris, les différents composants de la voie Notch à savoir, le récepteur Notch2, un ligand de Notch2 (Jadded1) et les cibles de la voie Notch (Hes1et Hey2) sont exprimés dans les cellules de pré-granulosa et/ou l'ovocyte de follicules primordiaux (Trombly et al., 2009). L'inhibition chimique de la voie Notch (inhibiteur de secrétase) dans des cultures d'ovaires de souriceaux nouveaux-nés entraîne une diminution drastique du nombre de follicules primordiaux et une augmentation du nombre de cellules germinales restant incluses dans les cordons ovigères (Trombly et al., 2009). L'ensemble de ces résultats montre un rôle de la voie Notch dans la formation des follicules primordiaux des mammifères.

\section{Le facteur FOXL2}

Dans les ovaires de souris Foxl2 ${ }^{-/-}$les ovocytes en croissance sont (et restent) entourés par une seule couche de cellules de la granulosa. Ces cellules épithéliales sont pléiomorphes et souvent aplaties, rappelant celles des follicules primordiaux. Cela indique que le programme de différenciation de la granulosa a été sévèrement altéré dès les premiers stades de la folliculogenèse. En dépit de ces anomalies des cellules somatiques, la morphologie des ovaires et des ovocytes Foxl2 $^{-1-}$ à la naissance est apparemment normale.

À 8 semaines, l'ovaire de type sauvage montre un éventail de tailles et de stades de l'ovocyte et du follicule (follicules primordiaux principalement avec des diamètres ovocytaires $<20 \mu \mathrm{m}$ ), tandis que les ovocytes chez le mutant ont en général des diamètres $>20 \mu \mathrm{m}$ et nombre d'entre eux sont en apoptose. Les anomalies morphologiques et les altérations de la croissance de l'ovocyte suggèrent un défaut de formation du follicule primaire. Chez le mutant, les ovocytes restent groupés (jusqu'à 10 ovocytes) et sont entourés par une couche de cellules de soutien. Ces structures persistent jusqu'à 8 semaines après la naissance et correspondent à des amas d'ovocytes et de cordons ovigères non fragmentés. Ces données montrent que FOXL2 est nécessaire pour la formation de follicules primordiaux (Uda et al., 2004).

\section{Le maintien du stock de follicules primordiaux}

\section{L'hormone anti-Müllerienne}

En plus de son rôle dans la régression des canaux de Müller chez le mâle, l'AMH (Anti-Müllerian Hormone) est un facteur de croissance impliqué dans le maintien du stock de follicules primordiaux par inhibition de la croissance folliculaire. Le transcrit de l'Amh est détecté à 3 jours post-partum dans les cellules de la granulosa des follicules primaires et jusqu'au stade antral chez la souris (Durlinger et al., 1999). Les ovaires des souris invalidées pour ce gène sont fertiles mais les femelles $A \mathrm{mh}^{-1-}$ ont un nombre de follicules primordiaux beaucoup plus faible que des souris sauvages et un nombre de follicules en croissance plus élevé; ces ovaires mutants perdent rapidement leurs follicules primordiaux (Durlinger et al., 1999). Chez la brebis, l'AMH est exprimée par les cellules de la granulosa des follicules en croissance (Bézard et al., 1988) et n'est détectable qu'à partir des stades follicules pré-antraux à 120 jours de gestation (Bézard et al., 1987 ; Payen et al., 1996).

\section{Les facteurs FOXO3A (Forkhead box 3a) et PTEN (phosphatase and tensin homolog)}

FOXO3A est un autre facteur qui intervient dans le maintien du stock de follicules primordiaux (Liu et al., 2006). Chez la souris, Foxo3a est exprimé par les ovocytes des follicules primordiaux et des follicules primaires. En revanche, il est absent dans les autres follicules en croissance. La délétion du gène Foxo3a montre que les ovaires des femelles Foxo $3 a^{-/-}$dès $14 \mathrm{jpp}$ ne contiennent pas de follicules primordiaux mais un nombre anormalement élevé de follicules primaires et secondaires conduisant à une stérilité des femelles (Castrillon et al., 2003). L'activation constitutive de Foxo3a chez la souris provoque un défaut de croissance des follicules primordiaux et une diminution de l'expression de Bmp15 et des connexines 37 et 43 (protéines de structure des jonctions qui relient l'ovocyte aux cellules de la granulosa), ces trois gènes étant impliqués dans la croissance folliculaire (Liu et al., 2007). L'activité de FOXO3A est régulée par la voie PI3K/AKT, elle-même activée par le facteur Kit/ Kit Ligand. Au sein des ovocytes des follicules primordiaux, l'activation d'AKT inhibe FOXO3A en la phosphorylant. Cette voie aboutit à la prolifération des cellules pré-granulosa et à la formation des follicules 


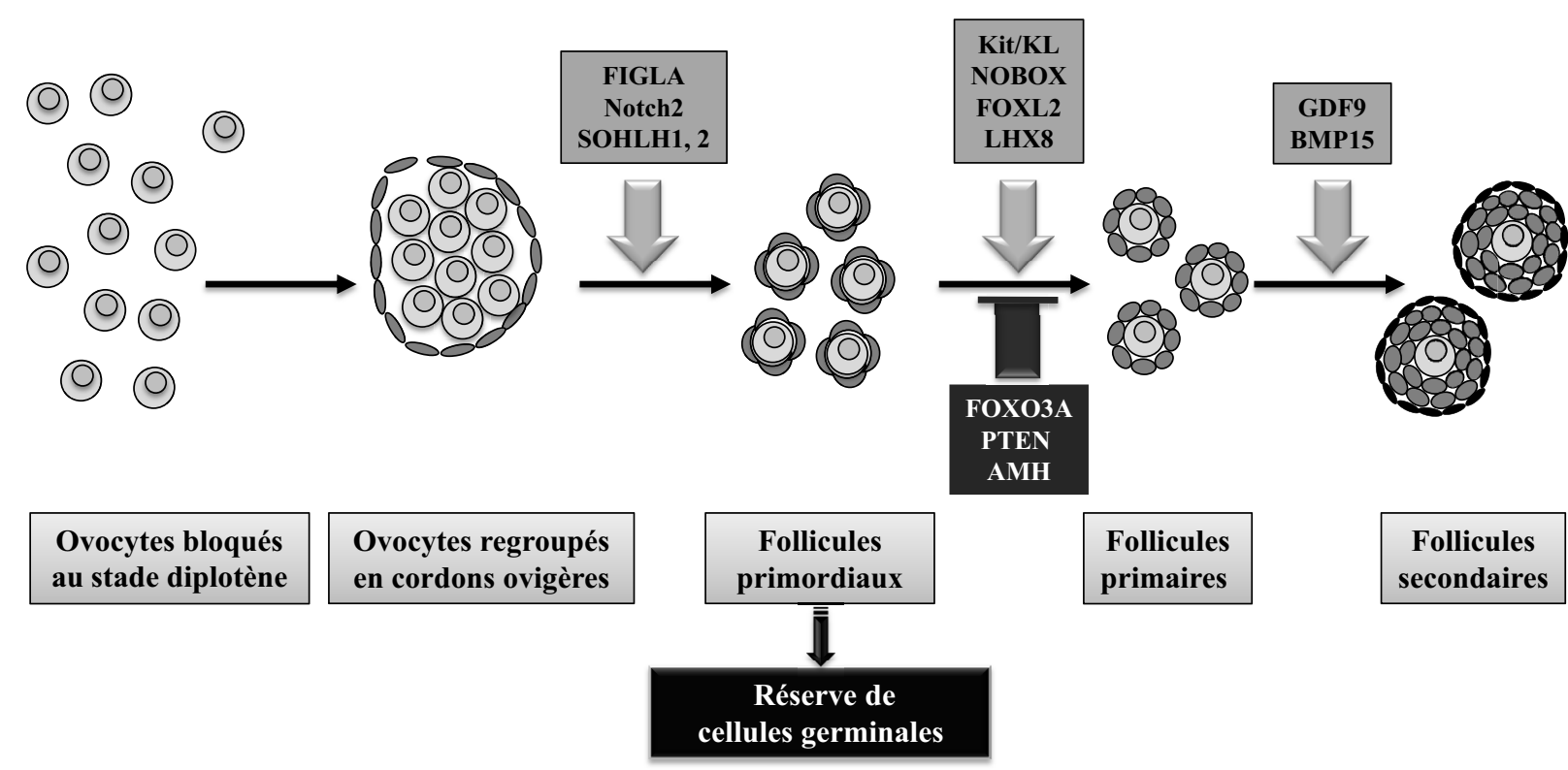

Fig. 3. Principaux facteurs impliqués dans la formation des follicules et le maintien de la réserve ovarienne. Plusieurs facteurs sont impliqués dans la formation des follicules primordiaux (FILGA, NOTCH2, SOHLH1 et 2, FOXL2), primaires (NOBOX, LHX8, cKIT/KL) ou secondaires (GDF9, BMP15) tandis que d'autres maintiennent le stock de follicules primordiaux en évitant leur différenciation (AMH, PTEN, FOXO3A).

primaires. Inversement, lorsqu'AKT est inactive, FOXO3A maintient le stock de follicules primordiaux : (i) en inhibant la transcription de $B m p 15, C x 37$ et $C x 43$ et (ii) en activant $p 27$ dont le rôle est d'inhiber la croissance folliculaire (Liu et al., 2007).

PTEN est un autre facteur présent dans l'ovocyte qui empêche l'activation des follicules en inhibant le signal issu de la voie PI3K. Une perte de PTEN dans les ovocytes de souris entraîne une croissance prématurée de tout le stock de follicules primordiaux suggérant que l'inhibition de la voie PI3K via PTEN permet de maintenir la réserve ovarienne de follicules primordiaux (John et al., 2008 ; Reddy et al., 2008).

Une fois les follicules primordiaux formés, ils constituent la réserve des gamètes femelles, ces follicules sortent ensuite de ce stock à chaque cycle pour subir des étapes de maturation folliculaire. Une grande partie des follicules ovariens disparaîtra par atrésie tout au long de la vie. Les différentes étapes de formation des follicules et les gènes qui les contrôlent sont présentées dans la figure 3 .

\section{Petits ARNs et développement ovarien}

Les petits ARN non codants régulent l'expression et la fonction des gènes dans de multiples tissus, dont l'ovaire (Torley et al., 2011 ; Tripurani et al., 2011) et l'ovocyte (Watanabe et al., 2008). Chez les mammifères, il existe 3 groupes de petits ARNs : les microARNs (miARNs), les piwi-interacting ARNs (piARNs) et les petits ARN interférents (siARNs) à la structure et aux caractéristiques différentes (tableau 4).

Les miARNs, incorporés en complexe ribonucléoprotéique (complexe RISC, composé en partie par des protéines de la famille Argonaute), répriment l'expression de gènes cibles en bloquant la traduction des ARN messagers et/ou en déstabilisant les transcrits via la région 3'UTR (voir références dans Ghildiyal \& Zamore, 2009 ; Katahira \& Yoneda, 2011). Une étude récente a montré l'expression de plusieurs miARNs dans les gonades foetales ovines. Plusieurs gènes ont été identifiés comme cibles de ces miARNs, il s'agit de ceux du récepteur des oestrogènes ESR1 (miARN : miR-22), de l'aromatase CYP19A1 (Let 7a, c, d, e, g), de la follistatine FST (miR-410), et de la protéine WNT4 (miR-211) (Torley et al., 2011).

Les siARNs répriment les gènes hôtes, les éléments transposables (ETs) et les virus (Bartel, 2004).

Les piARNs sont exprimés spécifiquement dans la lignée germinale mâle du testicule, suggérant un rôle essentiel au cours de la spermatogenèse (Aravin et al., 2006 ; Girard et al., 2006 ; Grivna et al., 2006 ; Watanabe et al., 2006). Ils interagissent avec une 
Tableau 4. Caractéristiques des petits ARNs non codants de mammifères.

\begin{tabular}{|c|c|c|c|}
\cline { 2 - 4 } \multicolumn{1}{c|}{} & siARN & miARN & piARN \\
\hline Longueur $(\mathrm{nt})$ & $\approx 21$ & $\approx 22$ & $\approx 24-32$ \\
\hline Biosynthèse & Dépendante de l'endonucléase DICER & Indépendante de DICER \\
\hline \multirow{2}{*}{ Fonctionnement } & \multicolumn{2}{|c|}{ Association en complexe multi-protéines (ribonucléoprotéines) } \\
\cline { 2 - 4 } & \multicolumn{2}{|c|}{$\rightarrow$ Famille des protéines Argonaute } \\
\hline $\begin{array}{c}\text { Protéines Argonaute } \\
\text { du complexe }\end{array}$ & \multicolumn{2}{|c|}{ Complexe RISC } & Protéines PIWI \\
\hline Rôle fonctionnel & Clivage des ARNm cibles & $\begin{array}{c}\text { Déstabilisation des ARNm } \\
\text { Blocage de traduction }\end{array}$ & $\begin{array}{c}\text { Suppression des éléments transposables } \\
\text { Maintenance de l'intégrité } \\
\text { du génome }\end{array}$ \\
\hline
\end{tabular}

Tableau 5. Principaux gènes intervenant dans la voie des piARNs de la lignée germinale mâle de souris.

\begin{tabular}{|c|c|c|c|}
\hline Nom des gènes & Domaine protéique & $\begin{array}{c}\text { Effets de l'invalidation } \\
\text { chez la souris }\end{array}$ & Références \\
\hline Maelstrom & HMG box & Mâle stérile & $\begin{array}{l}\text { Costa et al. }(2006) \\
\text { Soper et al. }(2008)\end{array}$ \\
\hline Miwi/Piwil1, Mili/Piwil2 & Paz et PIWI & Mâle stérile & $\begin{array}{c}\text { Grivna et al. (2006) } \\
\text { Kuramochi-Miyagawa et al. (2004) }\end{array}$ \\
\hline$M v h$ & ARN hélicase & Mâle stérile & Kuramochi-Miyagawa et al. (2010) \\
\hline Mov10L1 & DExD-box hélicase & Mâle stérile & $\begin{array}{l}\text { Frost et al. }(2010) \\
\text { Zheng et al. }(2010)\end{array}$ \\
\hline Tdrd1/MTR-1, Tdrd6, Tdrd7 & Domaine Tudor répété & Mâle stérile (Tdrd1) & $\begin{array}{l}\text { Chuma et al. }(2003,2006) \\
\text { Hosokawa et al. }(2007)\end{array}$ \\
\hline
\end{tabular}

sous-famille de protéines Argonaute, les PIWI protéines (chez la souris : MIWI, MILI, et MIWI2); chez l'Homme et les bovins (PIWIL1, PIWIL2 et PIWIL4 respectivement), une quatrième protéine de la famille PIWI a été décrite, PIWIL3, qui n'est pas retrouvée chez les rongeurs (Sasaki et al., 2003). Actuellement, une seule de ces protéines (MILI) a été observée dans la lignée germinale femelle chez la souris (Watanabe et al., 2008). Dans cette espèce, l'invalidation de chacune des protéines PIWI ou des protéines qui leur sont associées (MOV10L1, MVH, TDRD1) conduit à une activation des éléments transposables (ETs), un arrêt de spermatogenèse et une stérilité des mâles (Deng \& Lin, 2002 ; Kuramochi-Miyagawa et al., 2004 ; Carmell et al., 2007) suggérant la répression des ETs par les piARNs. Le tableau 5 présente les différentes protéines associées à la machinerie des piARNs de la lignée germinale mâle de souris. Le rôle des piARNs dans la lignée germinale femelle n'a pas été étudié chez les mammifères.

Ces recherches sur les petits ARNs montrent de nouvelles voies de régulation de l'expression des gènes au cours de la différenciation ovarienne, qui font appel au blocage de la traduction, à la déstabilisation des ARNm, au clivage des ARNm cibles, à la répression des éléments transposables, et à la méthylation de l'ADN. L'identification de nouveaux petits ARNs non codants au sein des gonades fotales femelles (miRNome, piARNs) va croître dans les prochaines années, et apporter des connaissances nouvelles sur le contrôle du développement de la lignée germinale femelle et de l'ovaire.

\section{Conclusion}

Des analyses sur les modèles animaux mutants ont montré que les cellules de la granulosa issues de souris doubles mutantes FoxL2/Wnt4 acquièrent des caractéristiques de cellules de Sertoli avant la naissance, à savoir une forte expression de Sox 9, Dmrt1 ainsi que d'autres gènes spécifiques de la voie de différenciation testiculaire, ce que ne fait pas la simple inactivation de Foxl2 (Ottolenghi et al., 2007). Par ailleurs, il a été montré que dans les gonades XX des chèvres PIS $^{-/}$n'exprimant pas FOXL2, Rspo1 était 


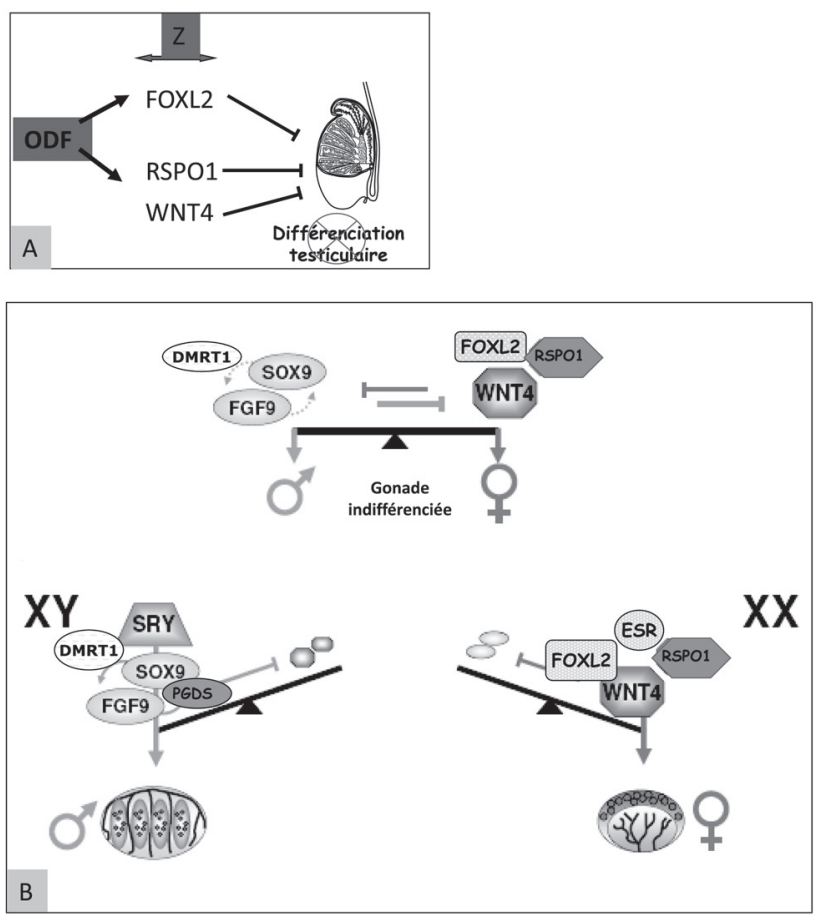

Fig. 4. Résumé des mécanismes génétiques contrôlant la différenciation ovarienne. A - Plusieurs gènes $\mathrm{Z}$ ont été identifiés : FoxL2, Rspo1, Wnt4, $\beta$-catenin. Deux questions restent posées : existe-t-il un facteur déterminant l'ovaire (Ovarian Determing Factor) à la tête de ces cascades géniques et existe-t-il d'autres gènes $Z$ non encore identifiés ? $\mathrm{B}$ - En fonction du sexe chromosomique (XX ou XY), des cascades géniques vont être initiées au sein des cellules somatiques des gonades indifférenciées. Chez le mâle, $S R Y$ déclenche l'allumage du gène $S O X 9$ qui va entraîner la différenciation des cellules de soutien en cellules de Sertoli et bloquer celle aboutissant aux cellules de granulosa. À l'inverse, chez la femelle, plusieurs cascades vont être initiées induisant le compartiment somatique à s'engager dans la voie femelle. Cette balance des sexes présente une certaine plasticité tout au long de la vie.

exprimé dans les stades précoces (Kocer et al., 2008). Il semble donc que FOXL2 et RSPO1/WNT4/ $\beta$ caténine agissent par deux voies indépendantes. L'importance relative de l'une ou l'autre voie à des moments clés du développement ovarien pouvant être différente en fonction des espèces. C'est ce que nous montrent les différences de phénotypes observées dans l'inactivation de FOXL2 entre la chèvre et la souris. La question du rôle de Foxl2 dans l'ovaire murin dès 12,5 jpc reste posée.

Il est également intéressant de noter que, bien après la différenciation de l'ovaire au cours de la vie embryonnaire, il est encore possible de transdifférencier les cellules de granulosa en cellules de Sertoli chez l'adulte par inactivation conditionnelle de Foxl2 et d'obtenir in vivo une reprogrammation du lignage cellulaire de soutien de la gonade (Uhlenhaut et al., 2009). Cette reprogrammation est spécifique de ce type cellulaire.

Pour assurer un développement coordonné de l'ovaire, on peut imaginer que des boucles de régulation existent entre les deux voies dirigées par FOXL2 et RSPO1, bien que celles-ci n'aient pas encore été complètement démontrées. Des ARNs non codants ainsi que des miARNs contrôlent probablement l'expression des gènes de ces deux voies. Il reste à les identifier et comprendre comment ils agissent.

On peut aussi supposer que chacune de ces voies contrôle un lignage cellulaire distinct au sein des cellules somatiques de l'ébauche gonadique XX, bien que ces lignages cellulaires restent assez mal caractérisés chez la femelle (épithélium cœlomique ou mésonéphros), leur proportion au sein de l'ébauche gonadique XX pouvant varier entre les différentes espèces.

Cependant la question majeure qui reste posée concerne l'existence et la caractérisation d'un gène de détermination ovarienne chez les mammifères (équivalent au gène $S R Y$ chez le mâle) qui initierait et contrôlerait l'expression de FOXL2 et RSPO1 dans l'ébauche gonadique XX (figure 4). Découvrir ce gène et le mécanisme par lequel il active FOXL2 et RSPO1 reste le challenge des années à venir. L'étude de patients ou de modèles animaux atteints d'inversion sexuelle devrait être déterminante pour la découverte de ces mécanismes.

En ce qui concerne la différenciation des cellules germinales femelles, l'action de l'acide rétinoïque pour déclencher la méiose semble moins prépondérante qu'on aurait pu le penser il ya quelques années et là aussi des différences entre espèces existent et sont sources de controverses. Deux acteurs clés dans l'initiation méiotique sont Dazla et Stra8 et pour le moment, on ne connaît pas leur mécanisme d'action. Enfin, il reste à élucider le rôle des petits ARNs (miARN, siARN et piARN) dans la différenciation germinale femelle.

\section{Références}

Adelman C., Petrini J., ZIP4H (TEX11) deficiency in the mouse impairs meiotic double strand break repair and the regulation of crossing over. PLoS Genet, 2008, 4, e1000042.

Al-Agha O., Huwait H., Chow C., Yang W., Senz J., Kalloger S., Huntsman D., Young R., Gilks C., FOXL2 is a 
sensitive and specific marker for sex cord-stromal tumors of the ovary. Am J Surg Pathol, 2011, 35, 484-494.

Arango N., Lovell-Badge R., Behringer R., Targeted mutagenesis of the endogenous mouse Mis gene promoter, in vivo definition of genetic pathways of vertebrate sexual development. Cell, 1999, 99, 409-419.

Aravin A., Gaidatzis D., Pfeffer S., Lagos-Quintana M., Landgraf P., Iovino N., Morris P., Brownstein M., Kuramochi-Miyagawa S., Nakano T., Chien M., Russo J., Ju J., Sheridan R., Sander C., Zavolan M., Tuschl T., A novel class of small RNAs bind to MILI protein in mouse testes. Nature, 2006, 442, 203-207.

Baillet A., Mandon-Pépin B., Cabau C., Poumerol E., Pailhoux E., Cotinot C., Identification of transcripts involved in meiosis and follicle formation during ovine ovary development. BMC Genomics, 2008, 9, 436.

Baker S., Bronner C., Zhang L., Plug A., Robatzek M., Warren G., Elliott E., Yu J., Ashley T., Arnheim N., Flavell R., Liskay R., Male mice defective in the DNA mismatch repair gene PMS2 exhibit abnormal chromosome synapsis in meiosis. Cell, 1995, 82, 309-319.

Baltus A., Menke D., Hu Y., Goodheart M., Carpenter A., de Rooij D., Page D., In germ cells of mouse embryonic ovaries, the decision to enter meiosis precedes premeiotic DNA replication. Nat Genet, 2006, 38, 1430-1434.

Barr M., The sex chromosomes in evolution and in medicine. Can Med Assoc J, 1966, 95, 1137-1148.

Bartel D., MicroRNAs, genomics, biogenesis, mechanism, and function. Cell, 2004, 116, 281-297.

Batista F., Vaiman D., Dausset J., Fellous M., Veitia R., Potential targets of FOXL2, a transcription factor involved in craniofacial and follicular development, identified by transcriptomics. Proc Natl Acad Sci USA, 2007, 104, 3330-3335.

Bayne R.A., Martins da Silva S.J., Anderson R.A., Increased expression of the FIGLA transcription factor is associated with primordial follicle formation in the human fetal ovary. Mol Hum Reprod, 2004, 10, 373-381.

Benayoun B.A., Kalfa N., Sultan C., Veitia R.A., The forkhead factor FOXL2: a novel tumor suppressor? Biochim Biophys Acta, 2010, 1805, 1-5.

Benayoun B.A., Georges A.B., L'Hote D., Andersson N., Dipietromaria A., Todeschini A.L., Caburet S., Bazin C., Anttonen M., Veitia R.A., Transcription factor FOXL2 protects granulosa cells from stress and delays cell cycle, role of its regulation by the SIRT1 deacetylase. Hum Mol Genet, 2011, 20, 1673-1686.

Bernard P., Harley V.R., Wnt4 action in gonadal development and sex determination. Int J Biochem Cell Biol, 2007, 39, $31-43$.

Berta P., Hawkins J.R., Sinclair A.H., Taylor A., Griffiths B.L., Goodfellow P.N., Fellous M., Genetic evidence equating SRY and the testis-determining factor. Nature, 1990, 348, 448-450.
Bézard J., Vigier B., Tran D., Mauléon P., Josso N., Immunocytochemical study of anti-Mullerian hormone in sheep ovarian follicles during fetal and post-natal development. J Reprod Fertil, 1987, 80, 509-516.

Bézard J., Vigier B., Tran D., Mauléon P., Josso N., Antimullerian hormone in sheep follicles. Reprod Nutr Dev, 1988, 28, 1105-1112.

Bigliardi E., Parma P., Peressotti P., De Lorenzi L., Wohlsein P., Passeri B., Jottini S., Cantoni A.M., Clinical, genetic, and pathological features of male pseudohermaphroditism in dog. Reprod Biol Endocrinol, 2011, 9, 12.

Birk O.S., Casiano D.E., Wassif C.A., Cogliati T., Zhao L., Zhao Y., Grinberg A., Huang S., Kreidberg J.A., Parker K.L., Porter F.D., Westphal H., The LIM homeobox gene Lhx9 is essential for mouse gonad formation. Nature, 2000, 403, 909-913.

Bolcun-Filas E., Costa Y., Speed R., Taggart M., Benavente R., De Rooij D.G., Cooke H.J., SYCE2 is required for synaptonemal complex assembly, double strand break repair, and homologous recombination. J Cell Biol, 2007, 176, 741-747.

Bowles J., Knight D., Smith C., Wilhelm D., Richman J., Mamiya S., Yashiro K., Chawengsaksophak K., Wilson M.J., Rossant J., Hamada H., Koopman P., Retinoid signaling determines germ cell fate in mice. Science, 2006, 312, 596-600.

Bowles J., Feng C.W., Spiller C., Davidson T.L., Jackson A., Koopman P., FGF9 suppresses meiosis and promotes male germ cell fate in mice. Dev Cell, 2010, 19, 440-449.

Brennan J., Capel B., One tissue, two fates, molecular genetic events that underlie testis versus ovary development. Nat Rev Genet, 2004, 5, 509-521.

Capel B., The battle of the sexes. Mech Dev, 2000, 92, 89-103.

Carmell M.A., Girard A., van de Kant H.J., Bourc'his D., Bestor T.H., de Rooij D.G., Hannon G.J., MIWI2 is essential for spermatogenesis and repression of transposons in the mouse male germline. Dev Cell, 2007, $12,503-514$.

Castrillon D.H., Miao L., Kollipara R., Horner J.W., DePinho R.A., Suppression of ovarian follicle activation in mice by the transcription factor Foxo3a. Science, 2003, 301, 215218.

Chassot A.A., Ranc F., Grégoire E.P., Roepers-Gajadien H.L., Taketo M.M., Camerino G., de Rooij D.G., Schedl A., Chaboissier M.C., Activation of beta-catenin signaling by Rspo1 controls differentiation of the mammalian ovary. Hum Mol Genet, 2008, 17, 1264-1277.

Childs A.J., Cowan G., Kinnell H.L., Anderson R.A., Saunders P.T., Retinoic Acid signalling and the control of meiotic entry in the human fetal gonad. PLoS One, 2011, 6, e20249.

Choi Y., Yuan D., Rajkovic A., Germ cell-specific transcriptional regulator sohlh2 is essential for early mouse folliculogenesis and oocyte-specific gene expression. Biol Reprod, 2008, 79, 1176-1182. 
Chuma S., Hiyoshi M., Yamamoto A., Hosokawa M., Takamune K., Nakatsuji N., Mouse Tudor Repeat-1 (MTR-1) is a novel component of chromatoid bodies/ nuages in male germ cells and forms a complex with snRNPs. Mech Dev, 2003, 120, 979-990.

Chuma S., Hosokawa M., Kitamura K., Kasai S., Fujioka M., Hiyoshi M., Takamune K., Noce T., Nakatsuji N., Tdrd1/ Mtr-1, a tudor-related gene, is essential for male germcell differentiation and nuage/germinal granule formation in mice. Proc Natl Acad Sci USA, 2006, 103, 15894-15899.

Combes A.N., Spiller C.M., Harley V.R., Sinclair A.H., Dunwoodie S.L., Wilhelm D., Koopman P., Gonadal defects in Cited2-mutant mice indicate a role for SF1 in both testis and ovary differentiation. Int J Dev Biol, 2010, 54, 683-689.

Coré N., Joly F., Boned A., Djabali M., Disruption of E2F signaling suppresses the INK4a-induced proliferative defect in M33-deficient mice. Oncogene, 2004, 23, 76607668 .

Costa Y., Speed R.M., Gautier P., Semple C.A., Maratou K., Turner J.M., Cooke H.J., Mouse MAELSTROM, the link between meiotic silencing of unsynapsed chromatin and microRNA pathway? Hum Mol Genet, 2006, 15, 23242334.

Crisponi L., Deiana M., Loi A., Chiappe F., Uda M., Amati P., Bisceglia L., Zelante L., Nagaraja R., Porcu S., Ristaldi M.S., Marzella R., Rocchi M., Nicolino M., Lienhardt-Roussie A., Nivelon A., Verloes A., Schlessinger D., Gasparini P., Bonneau D., Cao A., Pilia G., The putative forkhead transcription factor FOXL2 is mutated in blepharophimosis/ptosis/epicanthus inversus syndrome. Nat Genet, 2001, 27, 159-166.

Cui S., Ross A., Stallings N., Parker K.L., Capel B., Quaggin S.E., Disrupted gonadogenesis and male-to-female sex reversal in Pod1 knockout mice. Development, 2004, 131, 4095-4105.

De Baere E., Lemercier B., Christin-Maitre S., Durval D., Messiaen L., Fellous M., Veitia R., FOXL2 mutation screening in a large panel of POF patients and XX males. J Med Genet, 2002, 39, e43.

de Vries S.S., Baart E.B., Dekker M., Siezen A., de Rooij D.G., de Boer P., te Riele H., Mouse MutS-like protein Msh5 is required for proper chromosome synapsis in male and female meiosis. Genes Dev, 1999, 13, 523-531.

de Vries F.A., de Boer E., van den Bosch M., Baarends W.M., Ooms M., Yuan L., Liu J.G., van Zeeland A.A., Heyting C., Pastink A., Mouse Sycp1 functions in synaptonemal complex assembly, meiotic recombination, and XY body formation. Genes Dev, 2005, 19, 1376-1389.

Deng W. Lin H., miwi, a murine homolog of piwi, encodes a cytoplasmic protein essential for spermatogenesis. Dev Cell, 2002, 2, 819-830.

DiNapoli L., Capel B., SRY and the standoff in sex determination. Mol Endocrinol, 2008, 22, 1-9.
Dissen G.A., Hirshfield A.N., Malamed S., Ojeda S.R., Expression of neurotrophins and their receptors in the mammalian ovary is developmentally regulated, changes at the time of folliculogenesis. Endocrinology, 1995, 136, 4681-4692.

Dissen G.A., Romero C., Hirshfield A.N., Ojeda S.R., Nerve growth factor is required for early follicular development in the mammalian ovary. Endocrinology, 2001, 142, 20782086.

Dong J., Albertini D.F., Nishimori K., Kumar T.R., Lu N., Matzuk M.M., Growth differentiation factor-9 is required during early ovarian folliculogenesis. Nature, 1996, 383 , $531-535$.

Durlinger A.L., Kramer P., Karels B., de Jong F.H., Uilenbroek J.T., Grootegoed J.A., Themmen A.P., Control of primordial follicle recruitment by antiMullerian hormone in the mouse ovary. Endocrinology, 1999, 140, 5789-5796.

Edelmann W., Cohen P.E., Kane M., Lau K., Morrow B., Bennett S., Umar A., Kunkel T., Cattoretti G., Chaganti R., Pollard J.W., Kolodner R.D., Kucherlapati R., Meiotic pachytene arrest in MLH1-deficient mice. Cell, 1996, 85, 1125-1134.

Edson M.A., Nagaraja A.K., Matzuk M.M., The mammalian ovary from genesis to revelation. Endocr Rev, 2009, 30, $624-712$.

Elvin J.A., Clark A.T., Wang P., Wolfman N.M., Matzuk M.M., Paracrine actions of growth differentiation factor-9 in the mammalian ovary. Mol Endocrinol, 1999, 6, 1035-1048.

Frost R.J., Hamra F.K., Richardson J.A., Qi X., Bassel-Duby R., Olson E.N., MOV10L1 is necessary for protection of spermatocytes against retrotransposons by Piwiinteracting RNAs. Proc Natl Acad Sci USA, 2010, 107, 11847-11852.

Garcia-Ortiz J.E., Pelosi E., Omari S., Nedorezov T., Piao Y., Karmazin J., Uda M., Cao A., Cole S.W., Forabosco A., Schlessinger D., Ottolenghi C., Foxl2 functions in sex determination and histogenesis throughout mouse ovary development. BMC Dev Biol, 2009, 9, 36.

George F.W., Wilson J.D., Conversion of androgen to estrogen by the human fetal ovary. J Clin Endocrinol Metab, 1978, 47, 550-555.

Ghildiyal M., Zamore P.D., Small silencing RNAs, an expanding universe. Nat Rev Genet, 2009, 10, 94-108.

Girard A., Sachidanandam R., Hannon G.J., Carmell M.A., A germline-specific class of small RNAs binds mammalian Piwi proteins. Nature, 2006, 442, 199-202.

Goodfellow P.N., Lovell-Badge R., SRY and sex determination in mammals. Annu Rev Genet, 1993, 27, 71-92.

Greenbaum M.P., Yan W., Wu M.H., Lin Y.N., Agno J.E., Sharma M., Braun R.E., Rajkovic A., Matzuk M.M., TEX14 is essential for intercellular bridges and fertility in male mice. Proc Natl Acad Sci USA, 2006, 103, 49824987. 
Grivna S.T., Beyret E., Wang Z., Lin H., A novel class of small RNAs in mouse spermatogenic cells. Genes Dev, 2006, 20, 1709-1714

Hammes A., Guo J.K., Lutsch G., Leheste J.R., Landrock D., Ziegler U., Gubler M.C., Schedl A., Two splice variants of the Wilms' tumor 1 gene have distinct functions during sex determination and nephron formation. Cell, 2001, 106, 319-329.

Hanley N.A., Ball S.G., Clement-Jones M., Hagan D.M., Strachan T., Lindsay S., Robson S., Ostrer H., Parker K.L., Wilson D.I., Expression of steroidogenic factor 1 and Wilms' tumour 1 during early human gonadal development and sex determination. Mech Dev, 1999, 87, $175-180$

Hes O., Vanecek T., Petersson F., Grossmann P., Hora M., Perez Montiel D.M., Steiner P., Dvorak M., Michal M., Mutational analysis (c.402C $>$ G) of the FOXL2 gene and immunohistochemical expression of the FOXL2 protein in testicular adult type granulosa cell tumors and incompletely differentiated sex cord stromal tumors. Appl Immunohistochem Mol Morphol, 2011, 19, 347-351.

Horie K., Takakura K., Taii S., Narimoto K., Noda Y., Nishikawa S., Nakayama H., Fujita J., Mori T., The expression of c-kit protein during oogenesis and early embryonic development. Biol Reprod, 1991, 4, 547-552.

Hosokawa M., Shoji M., Kitamura K., Tanaka T., Noce T., Chuma S., Nakatsuji N., Tudor-related proteins TDRD1/ MTR-1, TDRD6 and TDRD7/TRAP, domain composition, intracellular localization, and function in male germ cells in mice. Dev Biol, 2007, 301, 38-52.

Ikeda Y., Luo X., Abbud R., Nilson J.H., Parker K.L., The nuclear receptor steroidogenic factor 1 is essential for the formation of the ventromedial hypothalamic nucleus. $\mathrm{Mol}$ Endocrinol, 1995, 9, 478-486.

Ingraham H.A., Lala D.S., Ikeda Y., Luo X., Shen W.H., Nachtigal M.W., Abbud R., Nilson J.H., Parker K.L., The nuclear receptor steroidogenic factor 1 acts at multiple levels of the reproductive axis. Genes Dev, 1994, 8, 23022312.

Jacobs P.A., Strong J.A., A case of human intersexuality having a possible XXY sex-determining mechanism. Nature, 1959, 183, 302-303.

Jamieson S., Butzow R., Andersson N., Alexiadis M., UnkilaKallio L., Heikinheimo M., Fuller P.J., Anttonen M., The FOXL2 C134W mutation is characteristic of adult granulosa cell tumors of the ovary. Mod Pathol, 2010, 23, 1477-1485

Jeays-Ward K., Hoyle C., Brennan J., Dandonneau M., Alldus G., Capel B., Swain A., Endothelial and steroidogenic cell migration are regulated by WNT4 in the developing mammalian gonad. Development, 2003, $130,3663-3670$.

John G.B., Gallardo T.D., Shirley L.J., Castrillon D.H., Foxo3 is a PI3K-dependent molecular switch controlling the initiation of oocyte growth. Dev Biol, 2008, 321, 197-204.
Jordan B.K., Mohammed M., Ching S.T., Delot E., Chen X.N., Dewing P., Swain A., Rao P.N., Elejalde B.R., Vilain E., Up-regulation of WNT-4 signaling and dosagesensitive sex reversal in humans. Am J Hum Genet, 2001, $68,1102-1109$

Joshi S., Davies H., Sims L.P., Levy S.E., Dean J., Ovarian gene expression in the absence of FIGLA, an oocytespecific transcription factor. BMC Dev Biol, 2007, 7, 67.

Jost A., Recherches sur la différenciation sexuelle de l'embryon de lapin. III Rôle des gonades foetales dans la différenciation sexuelle somatique. Arch Anat Micr Morph Expérim, 1947, 36, 271-318.

Jost A., A new look at the mechanisms controlling sex differentiation in mammals. Johns Hopkins Med J, 1972, $130,38-53$.

Katahira J., Yoneda Y., Nucleocytoplasmic Transport of MicroRNAs and Related Small RNAs. Traffic, 2011, DOI: $10.1111 /$ j.1600-0854.

Katoh-Fukui Y., Tsuchiya R., Shiroishi T., Nakahara Y., Hashimoto N., Noguchi K., Higashinakagawa T., Maleto-female sex reversal in M33 mutant mice. Nature, 1998, 393, 688-692

Kim Y., Capel B., Balancing the bipotential gonad between alternative organ fates, a new perspective on an old problem. Dev Dyn, 2006, 235, 2292-2300.

Kim J.W., Bak C.W., Chin M.U., Cha D.H., Yoon T.K., Shim S.H., SRY-negative 46, XX infertile male with Leydig cell hyperplasia, clinical, cytogenetic, and molecular analysis and review of the literature. Fertil Steril, 2010a, 94, 753 e755-759.

Kim T., Sung C.O., Song S.Y., Bae D.S., Choi Y.L., FOXL2 mutation in granulosa-cell tumours of the ovary. Histopathology, 2010b, 56, 408-410.

Kim J.H., Yoon S., Park M., Park H.O., Ko J.J., Lee K., Bae J., Differential apoptotic activities of wild-type FOXL2 and the adult-type granulosa cell tumor-associated mutant FOXL2 (C134W). Oncogene, 2011, 30, 16531663.

Kneitz B., Cohen P.E., Avdievich E., Zhu L., Kane M.F., Hou H., Jr., Kolodner R.D., Kucherlapati R., Pollard J.W., Edelmann W., MutS homolog 4 localization to meiotic chromosomes is required for chromosome pairing during meiosis in male and female mice. Genes Dev, 2000, 14, 1085-1097.

Kocer A., Pinheiro I., Pannetier M., Renault L., Parma P., Radi O., Kim K.A., Camerino G., Pailhoux E., R-spondin1 and FOXL2 act into two distinct cellular types during goat ovarian differentiation. BMC Dev Biol, 2008, 8, 36 .

Koopman P., Gubbay J., Vivian N., Goodfellow P., LovellBadge R., Male development of chromosomally female mice transgenic for Sry. Nature, 1991, 351, 117-121.

Koubova J., Menke D.B., Zhou Q., Capel B., Griswold M.D., Page D.C., Retinoic acid regulates sex-specific timing of 
meiotic initiation in mice. Proc Natl Acad Sci USA, 2006, 103, 2474-2479.

Kreidberg J.A., Sariola H., Loring J.M., Maeda M., Pelletier J., Housman D., Jaenisch R., WT-1 is required for early kidney development. Cell, 1993, 74, 679-691.

Kumar S., Chatzi C., Brade T., Cunningham T.J., Zhao X., Duester G., Sex-specific timing of meiotic initiation is regulated by Cyp26b1 independent of retinoic acid signalling. Nat Commun, 2011, 2, 151.

Kuramochi-Miyagawa S., Kimura T., Ijiri T.W., Isobe T., Asada N., Fujita Y., Ikawa M., Iwai N., Okabe M., Deng W., Lin H., Matsuda Y., Nakano T., Mili, a mammalian member of piwi family gene, is essential for spermatogenesis. Development, 2004, 131, 839-849.

Kuramochi-Miyagawa S., Watanabe T., Gotoh K., Takamatsu K., Chuma S., Kojima-Kita K., Shiromoto Y., Asada N., Toyoda A., Fujiyama A., Totoki Y., Shibata T., Kimura T., Nakatsuji N., Noce T., Sasaki H., Nakano $\mathrm{T}$., MVH in piRNA processing and gene silencing of retrotransposons. Genes Dev, 2010, 24, 887-892.

Larsson S.H., Charlieu J.P., Miyagawa K., Engelkamp D., Rassoulzadegan M., Ross A., Cuzin F., van Heyningen V., Hastie N.D., Subnuclear localization of WT1 in splicing or transcription factor domains is regulated by alternative splicing. Cell, 1995, 81, 391-401.

Le Bouffant R., Guerquin M.J., Duquenne C., Frydman N., Coffigny H., Rouiller-Fabre V., Frydman R., Habert R., Livera G., Meiosis initiation in the human ovary requires intrinsic retinoic acid synthesis. Hum Reprod, 2010, 25, 2579-2590.

Li H., Clagett-Dame M., Vitamin A deficiency blocks the initiation of meiosis of germ cells in the developing rat ovary in vivo. Biol Reprod, 2009, 81, 996-1001.

Liang L., Soyal S.M., Dean J., FIGalpha, a germ cell specific transcription factor involved in the coordinate expression of the zona pellucida genes. Development, 1997, 124, 4939-4947.

Libby B.J., De La Fuente R., O'Brien M.J., Wigglesworth K., Cobb J., Inselman A., Eaker S., Handel M.A., Eppig J.J., Schimenti J.C., The mouse meiotic mutation mei1 disrupts chromosome synapsis with sexually dimorphic consequences for meiotic progression. Dev Biol, 2002, 242, 174-187.

Lin Y., Gill M.E., Koubova J., Page D.C., Germ cell-intrinsic and -extrinsic factors govern meiotic initiation in mouse embryos. Science, 2008, 322, 1685-1687.

Lipkin S.M., Moens P.B., Wang V., Lenzi M., Shanmugarajah D., Gilgeous A., Thomas J., Cheng J., Touchman J.W., Green E.D., Schwartzberg P., Collins F.S., Cohen P.E., Meiotic arrest and aneuploidy in MLH3-deficient mice. Nat Genet, 2002, 31, 385-390.

Liu K., Rajareddy S., Liu L., Jagarlamudi K., Boman K., Selstam G., Reddy P., Control of mammalian oocyte growth and early follicular development by the oocyte PI3 kinase pathway, new roles for an old timer. Dev Biol, 2006, 299, 1-11.
Liu L., Rajareddy S., Reddy P., Du C., Jagarlamudi K., Shen Y., Gunnarsson D., Selstam G., Boman K., Liu K. Infertility caused by retardation of follicular development in mice with oocyte-specific expression of Foxo3a. Development, 2007, 134, 199-209.

Lu J., Chang P., Richardson J.A., Gan L., Weiler H., Olson E.N., The basic helix-loop-helix transcription factor capsulin controls spleen organogenesis. Proc Natl Acad Sci USA, 2000, 97, 9525-9530.

Lu J.R., Bassel-Duby R., Hawkins A., Chang P., Valdez R., Wu H., Gan L., Shelton J.M., Richardson J.A., Olson E.N., Control of facial muscle development by MyoR and capsulin. Science, 2002, 298, 2378-2381.

Luo X., Ikeda Y., Parker K.L., A cell-specific nuclear receptor is essential for adrenal and gonadal development and sexual differentiation. Cell, 1994, 77, 481-490.

Luo X., Ikeda Y., Lala D.S., Baity L.A., Meade J.C., Parker K.L., A cell-specific nuclear receptor plays essential roles in adrenal and gonadal development. Endocr Res, 1995 , $21,517-524$.

Maatouk D.M., DiNapoli L., Alvers A., Parker K.L., Taketo M.M., Capel B., Stabilization of beta-catenin in XY gonads causes male-to-female sex-reversal. Hum Mol Genet, 2008, 17, 2949-2955.

Mauléon P., Bézard J., Terqui M., Very early and transient 17 B-oestradiol secretion by fetal sheep ovary. In vitro study. Ann Biol Anim Bioch Biophys, 1977, 17, 399-401.

McElreavey K., Vilain E., Abbas N., Herskowitz I., Fellous M., A regulatory cascade hypothesis for mammalian sex determination: SRY represses a negative regulator of male development. Proc Natl Acad Sci USA, 1993, 90, 3368-3372.

Menke D.B., Page D.C., Sexually dimorphic gene expression in the developing mouse gonad. Gene Expr Patterns, 2002, 2, 359-367.

Menke A.L., van der Eb A.J., Jochemsen A.G., The Wilms' tumor 1 gene, oncogene or tumor suppressor gene? Int Rev Cytol, 1998, 181, 151-212.

Menke D.B., Koubova J., Page D.C., Sexual differentiation of germ cells in XX mouse gonads occurs in an anteriorto-posterior wave. Dev Biol, 2003, 262, 303-312.

Miyamoto N., Yoshida M., Kuratani S., Matsuo I., Aizawa S., Defects of urogenital development in mice lacking Emx2. Development, 1997, 124, 1653-1664.

Nakamura M., The mechanism of sex determination in vertebrates-are sex steroids the key-factor? J Exp Zool A Ecol Genet Physiol, 2010. 313, 381-398.

Nef S., Schaad O., Stallings N.R., Cederroth C.R., Pitetti J.L., Schaer G., Malki S., Dubois-Dauphin M., BoizetBonhoure B., Descombes P., Parker K.L., Vassalli J.D., Gene expression during sex determination reveals a robust female genetic program at the onset of ovarian development. Dev Biol, 2005, 287, 361-377.

Ottolenghi C., Pelosi E., Tran J., Colombino M., Douglass E., Nedorezov T., Cao A., Forabosco A., Schlessinger D., 
Loss of Wnt4 and Foxl2 leads to female-to-male sex reversal extending to germ cells. Hum Mol Genet, 2007, $16,2795-2804$.

Oulad-Abdelghani M., Bouillet P., Decimo D., Gansmuller A., Heyberger S., Dolle P., Bronner S., Lutz Y., Chambon P., Characterization of a premeiotic germ cell-specific cytoplasmic protein encoded by Stra8, a novel retinoic acid-responsive gene. J Cell Biol, 1996, 135, 469-477.

Pailhoux E., Parma P., Sundstrom J., Vigier B., Servel N., Kuopio T., Locatelli A., Pelliniemi L.J., Cotinot C., Time course of female-to-male sex reversal in $38 \mathrm{XX}$ fetal and postnatal pigs. Dev Dyn, 2001, 222, 328-340.

Pangas S.A., Choi Y., Ballow D.J., Zhao Y., Westphal H., Matzuk M.M., Rajkovic A., Oogenesis requires germ cellspecific transcriptional regulators Sohlh1 and Lhx8. Proc Natl Acad Sci USA, 2006, 103, 8090-8095.

Pannetier M., Fabre S., Batista F., Kocer A., Renault L., Jolivet G., Mandon-Pépin B., Cotinot C., Veitia R., Pailhoux E., FOXL2 activates P450 aromatase gene transcription, towards a better characterization of the early steps of mammalian ovarian development. $J \mathrm{Mol}$ Endocrinol, 2006, 36, 399-413.

Pannetier M., Pailhoux E., FOXL2, the gatekeeper of ovarian identity. Med Sci (Paris), 2010, 26, 470-473.

Parma P., Radi O., Vidal V., Chaboissier M.C., Dellambra E., Valentini S., Guerra L., Schedl A., Camerino G., Rspondin1 is essential in sex determination, skin differentiation and malignancy. Nat Genet, 2006, 38, 1304-1309.

Payen E., Pailhoux E., Abou Merhi R., Gianquinto L., Kirszenbaum M., Locatelli A., Cotinot C., Characterization of ovine SRY transcript and developmental expression of genes involved in sexual differentiation. Int J Dev Biol, 1996, 40, 567-575.

Pazin D.E., Albrecht K.H., Developmental expression of Smoc1 and Smoc2 suggests potential roles in fetal gonad and reproductive tract differentiation. Dev Dyn, 2009, $238,2877-2890$

Pittman D.L, Cobb J., Schimenti K.J., Wilson L.A., Cooper D.M., Brignull E., Handel M.A., Schimenti J.C., Meiotic prophase arrest with failure of chromosome synapsis in mice deficient for Dmc1, a germline-specific RecA homolog. Mol Cell, 1998, 1, 697-705.

Quaggin S.E., Schwartz L., Cui S., Igarashi P., Deimling J., Post M., Rossant J., The basic-helix-loop-helix protein pod1 is critically important for kidney and lung organogenesis. Development, 1999, 126, 5771-5783.

Rajkovic A., Pangas S.A., Ballow D., Suzumori N., Matzuk M.M., NOBOX deficiency disrupts early folliculogenesis and oocyte-specific gene expression. Science, 2004, 305, 1157-1159

Reddy P., Liu L., Adhikari D., Jagarlamudi K., Rajareddy S., Shen Y., Du C., Tang W., Hamalainen T., Peng S.L., Lan ZJ., Cooney AJ., Huhtaniemi I., Liu K., Oocyte-specific deletion of Pten causes premature activation of the primordial follicle pool. Science, 2008, 319, 611-613.
Reynolds N., Collier B., Bingham V., Gray N.K., Cooke H.J., Translation of the synaptonemal complex component Sycp3 is enhanced in vivo by the germ cell specific regulator Dazl. RNA, 2007, 13, 974-981.

Romanienko P.J., Camerini-Otero R.D., The mouse Spo11 gene is required for meiotic chromosome synapsis. $\mathrm{Mol}$ Cell, 2000, 6, 975-987.

Sadovsky Y., Crawford P.A., Woodson K.G., Polish J.A., Clements M.A., Tourtellotte L.M., Simburger K., Milbrandt J., Mice deficient in the orphan receptor steroidogenic factor 1 lack adrenal glands and gonads but express P450 side-chain-cleavage enzyme in the placenta and have normal embryonic serum levels of corticosteroids. Proc Natl Acad Sci USA, 1995, 92, 10939-10943.

Sasaki T., Shiohama A., Minoshima S., Shimizu N., Identification of eight members of the Argonaute family in the human genome small star, filled. Genomics, 2003, $82,323-330$.

Sawyer H.R., Smith P., Heath D.A., Juengel J.L., Wakefield S.J., McNatty K.P., Formation of ovarian follicles during fetal development in sheep. Biol Reprod, 2002, 66, 11341150.

Schmidt D., Ovitt C.E., Anlag K., Fehsenfeld S., Gredsted L., Treier A.C., Treier M., The murine winged-helix transcription factor Foxl2 is required for granulosa cell differentiation and ovary maintenance. Development, 2004, 131, 933-942.

Sekido R., Lovell-Badge R., Sex determination involves synergistic action of SRY and SF1 on a specific Sox9 enhancer. Nature, 2008, 453, 930-934.

Sekido R., Bar I., Narvaez V., Penny G., Lovell-Badge R., SOX9 is up-regulated by the transient expression of SRY specifically in Sertoli cell precursors. Dev Biol, 2004, 274, 271-279.

Shawlot W., Behringer R.R., Requirement for Lim1 in headorganizer function. Nature, 1995, 374, 425-430.

Schibler L., Cribiu E.P., Oustry-Vaiman A., Furet J.P., Vaiman D., Fine mapping suggests that the goat Polled Intersex Syndrome and the human Blepharophimosis Ptosis Epicanthus Syndrome map to a 100-kb homologous region. Genome Res, 2000,10, 311-318.

Sinclair A., Smith C., Females battle to suppress their inner male. Cell, 2009, 139, 1051-1053.

Sinclair A.H., Berta P., Palmer M.S., Hawkins J.R., Griffiths B.L., Smith M.J., Foster J.W., Frischauf A.M., LovellBadge R., Goodfellow P.N., A gene from the human sexdetermining region encodes a protein with homology to a conserved DNA-binding motif. Nature, 1990, 346, 240244.

Skrzypczak J., Pisarski T., Biczysko W., Kedzia H., Evaluation of germ cells development in gonads of human fetuses and newborns. Folia Histochem Cytochem (Krakow), 1981, 19, 17-24.

Smith C.A., Roeszler K.N, Bowles J., Koopman P., Sinclair A.H., Onset of meiosis in the chicken embryo, evidence of a role for retinoic acid. BMC Dev Biol, 2008a, 8, 85 . 
Smith C.A., Shoemaker C.M., Roeszler K.N., Queen J., Crews D., Sinclair A.H., Cloning and expression of RSpondin1 in different vertebrates suggests a conserved role in ovarian development. BMC Dev Biol, 2008b, 8, 72.

Soper S.F., van der Heijden G.W., Hardiman T.C., Goodheart M., Martin S.L., de Boer P., Bortvin A., Mouse maelstrom, a component of nuage, is essential for spermatogenesis and transposon repression in meiosis. Dev Cell, 2008, 15, 285-297.

Soyal S.M., Amleh A., Dean J., FIGalpha, a germ cell-specific transcription factor required for ovarian follicle formation. Development, 2000, 127, 4645-4654.

Suzuki A., Saga Y., Nanos2 suppresses meiosis and promotes male germ cell differentiation. Genes Dev, 2008, 22, 430-435.

Swain A, Lovell-Badge R., Mammalian sex determination, a molecular drama. Genes Dev, 1999, 13, 755-767.

Torley K.J., da Silveira J.C., Smith P., Anthony R.V., Veeramachaneni D.N., Winger Q.A., Bouma G.J. Expression of miRNAs in ovine fetal gonads, potential role in gonadal differentiation. Reprod Biol Endocrinol, 2011, 9, 2 .

Tripurani S.K., Lee K.B., Wee G., Smith G.W., Yao J. MicroRNA-196a regulates bovine newborn ovary homeobox gene (NOBOX) expression during early embryogenesis. BMC Dev Biol, 11, 25.

Trombly D.J., Woodruff T.K., Mayo K.E. Suppression of Notch signaling in the neonatal mouse ovary decreases primordial follicle formation. Endocrinology, 2009, 150, 1014-1024

Tsuzuki T., Fujii Y., Sakumi K., Tominaga Y., Nakao K., Sekiguchi M., Matsushiro A., Yoshimura Y., Morita T. Targeted disruption of the Rad51 gene leads to lethality in embryonic mice. Proc Natl Acad Sci USA, 1996, 93, 6236-6240.

Uda M., Ottolenghi C., Crisponi L., Garcia J.E., Deiana M., Kimber W., Forabosco A., Cao A., Schlessinger D., Pilia G., Foxl2 disruption causes mouse ovarian failure by pervasive blockage of follicle development. Hum Mol Genet, 2004, 13, 1171-1181.

Uhlenhaut N.H., Jakob S., Anlag K., Eisenberger T., Sekido R., Kress J., Treier A.C., Klugmann C., Klasen C., Holter N.I., Riethmacher D., Schutz G., Cooney A.J., LovellBadge R., Treier M., Somatic sex reprogramming of adult ovaries to testes by FOXL2 ablation. Cell, 2009, 139, 1130-1142.

Vaiman D., Pailhoux E., Mammalian sex reversal and intersexuality, deciphering the sex-determination cascade. Trends Genet, 2000, 16, 488-494.

Vainio S., Heikkila M., Kispert A., Chin N., McMahon A.P., Female development in mammals is regulated by Wnt-4 signalling. Nature, 1999, 397, 405-409.

Veitia R.A., FOXL2 versus SOX9, a lifelong "battle of the sexes". Bioessays, 2010, 32, 375-380.
Vizziano-Cantonnet D., Baron D., Mahé S., Cauty C., Fostier A., Guiguen Y., Estrogen treatment up-regulates female genes but does not suppress all early testicular markers during rainbow trout male-to-female gonadal transdifferentiation. J Mol Endocrinol, 2008, 41, 277-288.

Wallacides A., Chesnel A., Chardard D., Flament S., Dumond H., Evidence for a conserved role of retinoic acid in urodele amphibian meiosis onset. Dev Dyn, 2009, 238, 1389-1398.

Watanabe T., Takeda A., Tsukiyama T., Mise K., Okuno T., Sasaki H., Minami N., Imai H., Identification and characterization of two novel classes of small RNAs in the mouse germline, retrotransposon-derived siRNAs in oocytes and germline small RNAs in testes. Genes Dev, 2006, 20, 1732-1743.

Watanabe T., Totoki Y., Toyoda A., Kaneda M., KuramochiMiyagawa S., Obata Y., Chiba H, Kohara Y., Kono T., Nakano T., Surani M.A., Sakaki Y., Sasaki H., Endogenous siRNAs from naturally formed dsRNAs regulate transcripts in mouse oocytes. Nature, 2008, 453, 539-543.

Wilhelm D., Englert C., The Wilms tumor suppressor WT1 regulates early gonad development by activation of Sf1. Genes Dev, 2002, 16, 1839-1851.

Yang F., Eckardt S., Leu N.A., McLaughlin K.J., Wang P.J., Mouse TEX15 is essential for DNA double-strand break repair and chromosomal synapsis during male meiosis. $J$ Cell Biol, 2008, 180, 673-679.

Yao H.H., Matzuk M.M., Jorgez C.J., Menke D.B., Page D.C., Swain A., Capel B., Follistatin operates downstream of Wnt4 in mammalian ovary organogenesis. Dev Dyn, 2004, 230, 210-215.

Yoshida H., Takakura N., Kataoka H., Kunisada T., Okamura H., Nishikawa S.I., Stepwise requirement of c-kit tyrosine kinase in mouse ovarian follicle development. Dev Biol, 1997, 184, 122-137.

Yoshida K., Kondoh G., Matsuda Y., Habu T., Nishimune Y., Morita T., The mouse RecA-like gene Dmc1 is required for homologous chromosome synapsis during meiosis. Mol Cell, 1998, 1, 707-718.

Yoshino O., McMahon H.E., Sharma S., Shimasaki S., A unique preovulatory expression pattern plays a key role in the physiological functions of BMP-15 in the mouse. Proc Natl Acad Sci USA, 2006, 103, 10678-10683.

Yuan L., Liu J.G., Hoja M.R., Wilbertz J., Nordqvist K., Hoog C., Female germ cell aneuploidy and embryo death in mice lacking the meiosis-specific protein SCP3. Science, 2002, 296, 1115-1118.

Zheng K., Xiol J., Reuter M., Eckardt S., Leu N.A., McLaughlin K.J., Stark A., Sachidanandam R., Pillai R.S., Wang P.J., Mouse MOV10L1 associates with Piwi proteins and is an essential component of the Piwiinteracting RNA (piRNA) pathway. Proc Natl Acad Sci USA, 2010, 107, 11841-11846. 